\title{
Monkey Median Nerve Repaired by Nerve Graft or Collagen Nerve Guide Tube
}

\author{
S. J. Archibald, ${ }^{1}$ J. Shefner, ${ }^{4}$ C. Krarup, ${ }^{5}$ and R. D. Madison ${ }^{1,2,3}$
}

${ }^{1}$ Division of Neurosurgery and ${ }^{2}$ Department of Neurobiology, Duke University Medical Center, and ${ }^{3} T h e$ Research Service of the Veterans Affairs Medical Center, Durham, North Carolina, ${ }^{4}$ Department of Medicine (Neurology), Brigham and Women's Hospital and Harvard Medical School, Boston, Massachusetts, and ${ }^{5}$ Department of Clinical Neurophysiology, University Hospital, Copenhagen, Denmark

Nerve regeneration was followed in 15 median and 1 ulnar nerve of eight Macaca fascicularis monkeys by serial electrophysiological assessments over a period of three and a half years. Nerve gaps of $5 \mathrm{~mm}$ at the wrist were bridged by collagen-based nerve guides, nerve autografts, or direct suture repairs. Thenar muscle reinnervation occurred between $\mathbf{5 0}$ and $\mathbf{7 0} \mathrm{d}$ for all groups, indicating axonal elongation rates of approximately $1 \mathrm{~mm} / \mathrm{d}$. The recovery rates of the compound muscle action potential (CMAP) and the compound sensory action potential (CSAP) amplitudes were significantly slower after direct suture repair compared to the other two procedures, although the final levels of recovery were all comparable. Similar results were achieved in one median and one ulnar nerve following nerve guide repair of a $15 \mathrm{~mm}$ nerve gap. The functional reinnervation of Pacinian corpuscles was detected in all cases following either nerve graft or nerve guide repair, with similar amplitudes and latencies of the tactile evoked CSAP for both types of repair. Histological analysis demonstrated a significant increase in the number of myelinated axons in the median nerve distal to the nerve lesions following both nerve graft and nerve guide repairs compared to proximal and normal controls, with significant reductions of fiber diameter and corresponding increases in g-ratio. The return of a bimodal frequency distribution of myelinated axon fiber diameter was confirmed by three-dimensional surface plots which illustrate the frequency distribution of the relationship between fiber diameter and g-ratio. These combined results demonstrate that nerve regeneration after repair of a $5 \mathrm{~mm}$ nerve gap with a collagen nerve guide in the nonhuman primate is similar to that after graft repair, and the final level of physiological recovery for both repair procedures is comparable to direct suture repair of the median nerve.

[Key words: nerve regeneration, monkey, graft repair, en-

\footnotetext{
Received July 28, 1994; revised Dec. 27, 1994; accepted Jan. 3, 1994.

This study was supported by NIH Grant N\$22404-09 (R.M.), the Mcrit Review Program of the US Department of Veterans Affairs (R.M.), Integra Life Sciences (R.M.), the Muscular Dystrophy Association (C.K.), and the Danish Medical Research Council (C.K.). We thank Ms. Lisa Wrage for excellent technical assistance, and Dr. Robert Lacin for a critical reading of the manuscript. Correspondence should be addressed to Roger Madison, Ph.D., Division of Neurosurgery, Box 3807, Duke University Medical Center, Durham. NC 27710.

Copyright $@ 1995$ Society for Neuroscience $\quad 0270-6474 / 95 / 154109-15 \$ 05.00 / 0$
}

tubulation repair, motor action potential, sensory action potential, tactile stimulation, g-ratio]

Surveys of the clinical literature show that less than $25 \%$ of median nerve repair patients recover complete voluntary motor function and less than $3 \%$ recover full normal sensation (Mackinnon and Dellon, 1988; Cooney, 1991). It is generally accepted that the best mode of treatment is direct suture of the proximal and distal nerve stumps. However, cases of severe laceration and injury may result in a nerve gap which must be bridged. The standard surgical procedure in such instances involves harvesting one or more nerves from the patient (e.g., sural nerve) and using these autografts to repair the original nerve injury. The less than ideal clinical results of these procedures have served as the impetus to continue the search for alternative methods of repairing peripheral nerve injuries. One such alternative is the use of various "nerve conduits" which may replace the need for nerve grafting (Archibald et al., 1991).

There has been a recent resurgence of interest in nerve repair using artificial nerve conduits to guide regenerating axons (for reviews, see Lundborg, 1988; Fields et al., 1989; Madison et al., 1992). The current study demonstrates the efficacy of a collagenbased nerve guide conduit to repair a $5 \mathrm{~mm}$ nerve gap in the monkey median nerve. Physiological recovery after these repairs was followed using serial electrophysiological techniques over a period of approximately three and a half years after the initial surgery. The recovery of both experimental repair groups has been compared to the more standard procedure of direct suture repair. Previous studies have been ambiguous as to the extent to which peripheral sensory targets are adequately reinnervated by nerves repaired with nerve guides. Therefore, the reinnervation of Pacinian corpuscles was also examined by electrophysiological and histological techniques.

Physiological assessments can not definitively quantify the number, size, or degree of maturation of regenerated axons. Therefore, at the end of the physiological assessments quantitative axonal morphometrics were used to determine whether there were also comparable levels of recovery for axonal histological parameters between the nerves repaired with either a collagen nerve guide or nerve graft.

The results of these studies are the most extensive longitudinal data ever reported for nonhuman primate peripheral nerve repair and they suggest the utility for collagen-based nerve guides in human peripheral nerve repair. 


\section{Materials and Methods}

Bilateral median nerve sections and repairs were performed in eight Macaca fascicularis monkeys at staggered intervals of 150-200 d to avoid the possibility of simultaneous disability. Median nerve section at the wrist results in the loss of sensory innervation of the palmar surface and finger tips of digits I, II, and III, and the radial aspect of the palmar surface of digit IV. However, radial and ulnar innervation provide protective sensation to the dorsal surface of the hand and digits. Motor innervation of three thenar muscles and the lumbrical muscles of digits II and III is also interrupted, and primarily results in the loss of thumb apposition. Despite these sensory and motor deficits the animals could grasp the cage bars and normal behaviors such as feeding and grooming were not significantly affected. Surgical procedures, electrophysiological assessments, animal housing, and enrichment programs were approved by the Duke University Animal Care and Use Committee, and the animals were monitored by the veterinary staff on a daily basis.

The animals did not display distress or any secondary complications resulting from the median nerve lesion, such as self-mutilation, pressure ulcers, sensory neglect, or infection.

Nerve guides. Nerve guides were fabricated (Integra Lifesciences, Plainsboro, NJ) from highly purified Type I collagen $(<0.2 \%$ hexosamine and $<0.1 \%$ trichloroacetic acid-insoluble residues, with four or fewer tyrosine residues per molecule), derived from bovine deep flexor tendon. The fibrillar structure of the collagen was maintained throughout the processing permitting the construction of a tubular matrix which had adequate mechanical strength and defined permeability (Archibald et al., 1991; Li et al., 1992). The structural stability of the nerve guides was increased by gaseous formaldehyde cross-linking which also controlled the rate of in vivo resorption. Previous studies ( $\mathrm{Li}$ et al., 1992) have shown that the nerve guides are freely permeable to macromolecules as large as bovine serum albumin $(\mathrm{MW}=68 \mathrm{kDa})$.

Surgery. The surgical, electrophysiological and terminal procedures were performed under deep general anesthesia with ketamine $(12.0 \mathrm{mg} /$ $\mathrm{kg})$ and acepromazine maleate $(1.0 \mathrm{mg} / \mathrm{kg})$. Under aseptic conditions the median nerve was transected $2 \mathrm{~cm}$ above the wrist and a $5 \mathrm{~mm}$ section of nerve was removed, the median nerve was then mobilized within the muscle bed for approximately $5 \mathrm{~cm}$ to decrease potential tension at the repair site. In four cases, the nerve segment was removed, reversed, rotated $180^{\circ}$, and then reimplanted between the nerve stumps using 10-0 epineural sutures to serve as a "nerve autograft." In the contralateral wrist, the $5 \mathrm{~mm}$ nerve gap was bridged with a collagen nerve guide where a single 10-0 suture anchored each nerve stump within the nerve guide. Four additional median nerves in which the 5 $\mathrm{mm}$ deficit was repaired by direct suture served as positive controls for the physiological studies.

A different procedure was used in the ulnar nerve of one animal and the median nerve of another, both these nerves were transected and nerve gaps of $4 \mathrm{~mm}$ were bridged by polylactate nerve guides. The animals were then followed for $630-679 \mathrm{~d}$ at which time the polylactate nerve guide was removed and the proximal and distal ends of the nerve stumps were resected to normal tissue. The resulting gap of $15 \mathrm{~mm}$ was bridged by a collagen nerve guide. The contralateral median nerves received either a nerve guide or autograft repair as described above to bridge a $5 \mathrm{~mm}$ nerve gap.

Electrophysiological procedures. Following baseline measurements and the experimental nerve repair, a total of 293 physiological assessments were made between 6 and $1309 \mathrm{~d}$ after initial surgery $(87,80$, and 126 assessments were made in the nerve guide, nerve graft, and direct suture groups, respectively). Physiological assessments were performed under general anesthesia with the animal placed on insulating raw cotton wool (hydrophobic), and the arms maintained at a constant temperature of $35-36^{\circ} \mathrm{C}$ by an automatically controlled radiant heat source (DANTEC).

Motor conduction studies. The compound muscle action potential (CMAP) was recorded from the abductor pollicis brevis (APB) muscle using either a subcutaneous needle placed over the motor end-plate zone or a concentric needle placed within the muscle. The CMAP was amplified (DANTEC $15 \mathrm{C} 01,10 \mathrm{~Hz}-10 \mathrm{kHz}, 3 \mathrm{~dB}$ down) and recorded on an ink-jet writer or an $x-y$ plotter via a digital memory store (event or transient recorder). The peak-to-peak amplitude of the CMAP was measured, and the latency of the response was measured to the first deflection from the baseline.

The median nerve was electrically stimulated at the wrist distal to the nerve lesion by rectangular pulses with a duration of $0.1-0.2 \mathrm{msec}$ using a constant current stimulator and insulated steel needles $(0.7 \mathrm{~mm}$ in diameter with a $3 \mathrm{~mm}$ bared tip). The placement of the stimulating electrode close to the nerve was optimized by obtaining a threshold of activation of the CMAP of $\leq 0.6 \mathrm{~m} \Lambda$, and the anode was placed subcutaneously at a transverse distance of $10-20 \mathrm{~mm}$. After placement of the cathode, the stimulus current was increased above that which elicited a maximal CMAP. During early regeneration the threshold of nerve fibers is markedly elevated, and at this stage a maximal stimulus of 60 $\mathrm{mA}$ and a duration of $1 \mathrm{msec}$ was used to ascertain whether the muscle had become reinnervated. In a limited number of assessments, at 300 $400 \mathrm{~d}$ after nerve repair, the median nerve was also stimulated at the elbow and axilla using a similar procedure. Since the nerve at these sites was proximal to the nerve lesion, the stimulus threshold was normal even during early regeneration.

Sensory conduction studies. The electrode which was optimally placed to evoke the CMAP was kept in place and used to record the orthodromic compound sensory action potential (CSAP) evoked by stimulating nerve fibers in digit II through needle electrodes or a surface ring electrode placed at the mid-level of the proximal phalanx. Stimulation was also carried out with a needle electrode placed at the tip of the digit. The responses were amplified (DANTEC 15C02, 200-4000 $\mathrm{Hz}, 3 \mathrm{~dB}$ down), averaged (Nicolet 1074, sampling interval 20-40 $\mu \mathrm{sec}$ ), and recorded on a $x-y$ plotter. The CSAP was measured peakto-peak and the latency was measured to the first positive peak of the potential.

The impedance of the recording electrodes was reduced prior to use by passing an $\mathrm{AC}$ current of $50 \mathrm{~mA}$ through the electrodes for $30 \mathrm{sec}$ in a saline bath at $90^{\circ} \mathrm{C}$ (Buchthal and Rosenfalck, 1966).

Responses evoked by tactile stimulation. A discrete tactilc stimulus was applied to the distal pad of digit II by a circular probe having a surface area of $3.14 \mathrm{~mm}^{2}$ which delivered an indentation of $100 \mu \mathrm{m}$ at a rate of $400 \mu \mathrm{m} / \mathrm{msec}$. The stimulus duration was $500 \mathrm{msec}$ and was repeated at a rate of $1.5 \mathrm{~Hz}$. The stimulus parameters were optimized to avoid contamination by an "off-response" from stimulated receptors (Buchthal, 1982a,b). In order to avoid activation of joint receptors, the finger was firmly stabilized with a support and forceps holding the fingernail. In the neutral position the probe was placed just to touch, but not indent, the skin of the finger pad.

The response to tactile stimulation was recorded at the wrist, and occasionally also at the elbow, using the same electrode placement used to record the electrically evoked CSAP. To show the stability of the response, up to 512 responses were first summed and then another 512 were added to show that the anplitude of the response grew proportionately to the number of stimuli given with no increase in background "noise." The averaged response was rectified and integrated as described previously (Buchthal, 1982a,b).

The latency of the tactile response was measured to the first positive peak. To estimate the delay at the sensory receptor, the latency of the electrically evoked CSAP at the tip of digit II was subtracted from the latency of the response evoked by tactile stimulation, the result was used as an indirect measurement of the time taken for the sensory receptor to respond to the tactile stimulus, or the "receptor delay". Measurements were also made of both the peak-to-peak and the integrated amplitude of the rectified tactile polyphasic response to the last reproducible phase.

Morphometric analyses. Morphometric measurements were carried out on the nerves repaired by either a nerve graft or nerve guide; with samples taken $2 \mathrm{~cm}$ proximal and $2 \mathrm{~cm}$ distal to the suture lines. Five of the median nerve samples were from animals that underwent a nerve graft repair and were sacrificed after an average of $1342 \mathrm{~d}$ after surgery (range of 752-1783, SD of 373 d). Four median nerve samples were from animals which underwent a nerve guide repair and were sacrificed after an average of $1461 \mathrm{~d}$ after surgery (range of 1140-1644, SD of $207 \mathrm{~d})$. The secondary repairs of the $15 \mathrm{~mm}$ long nerve gaps were recovered for histology 1139 (median) and 879 (ulnar) d after the second surgery. An additional four normal median nerves acted as baseline controls.

Tissue processing. Under deep general anesthesia the animals were transcardially perfused with heparinized phosphate-buffered saline $(\mathrm{pH}$ 7.2) followed by $1 \%$ glutaraldehyde and $2 \%$ paraformaldehyde in 0.1 $\mathrm{M}$ phosphate buffer ( $\mathrm{pH}$ 7.2). The repaired nerves were exposed from the elbow to the distal end of the carpal tunnel and removed.

The digital nerves from digit III, normally innervated by the median nerve, were harvested from both hands of one animal, each having undergone nerve graft or nerve guide repair of the median nerve. As a 
Table 1. Statistical comparisons of the physiological measures

\begin{tabular}{|c|c|c|c|c|c|c|c|c|c|c|c|}
\hline \multirow[b]{2}{*}{ Variable } & \multicolumn{3}{|l|}{ Tube } & \multicolumn{3}{|l|}{ Graft } & \multicolumn{3}{|l|}{$\underline{\text { Suture }}$} & \multirow[b]{2}{*}{$q$} & \\
\hline & $\begin{array}{l}\text { Slope } \\
\left(b / x^{2}\right)\end{array}$ & $\begin{array}{l}\text { Elevation } \\
(a)\end{array}$ & $n$ & $\begin{array}{l}\text { Slope } \\
\left(b / x^{2}\right)\end{array}$ & $\begin{array}{l}\text { Elevation } \\
(a)\end{array}$ & $n$ & $\begin{array}{l}\text { Slope } \\
\left(b / x^{2}\right)\end{array}$ & $\begin{array}{l}\text { Elevation } \\
(a)\end{array}$ & $n$ & & \\
\hline $\begin{array}{l}\text { CMAP } \\
\text { latency }\end{array}$ & 7,026 & 2.46 & 77 & 7,994 & 2.19 & 76 & 6,061 & 2.64 & 92 & $\begin{array}{l}\mathrm{T} \text { vs } \mathrm{G} \\
\mathrm{T} \text { vs } \mathrm{S} \\
\mathrm{G} \text { vs } \mathrm{S}\end{array}$ & $\begin{array}{l}\text { NS } \\
\text { NS } \\
\text { NS }\end{array}$ \\
\hline $\begin{array}{l}\text { CMAP } \\
\text { amplitude }\end{array}$ & $-30,670$ & 26.3 & 78 & $-36,400$ & 23.4 & 76 & $-125,000$ & 27.5 & 90 & $\begin{array}{l}\mathrm{T} \text { vs } \mathrm{G} \\
\mathrm{T} \text { vs } \mathrm{S} \\
\mathrm{G} \text { vs } \mathrm{S}\end{array}$ & $\begin{array}{c}\text { NS } \\
<0.001 \\
<0.001\end{array}$ \\
\hline SNCV & -13.190 & 42.7 & 75 & $-10,800$ & 44.4 & 69 & $-15,150$ & 41.7 & 110 & $\begin{array}{l}\text { T vs } G \\
\text { T vs } S \\
G \text { vs } S\end{array}$ & $\begin{array}{l}\text { NS } \\
\text { NS } \\
\text { NS }\end{array}$ \\
\hline $\begin{array}{l}\text { CSAP } \\
\text { amplitude }\end{array}$ & $-75,570$ & 13.7 & 74 & $-83,080$ & 18.2 & 75 & $-118,900$ & 14.7 & 110 & $\begin{array}{l}\text { T vs } G \\
T \text { vs } S \\
G \text { vs } S\end{array}$ & $\begin{array}{c}\text { NS } \\
<0.05 \\
<0.05\end{array}$ \\
\hline SNCV tip & $-13,830$ & 41.3 & 24 & $-11,970$ & 40.5 & 28 & & & & & \\
\hline $\begin{array}{l}\text { CSAP tip } \\
\text { amplitude }\end{array}$ & $-33,290$ & 2.4 & 24 & $-35,640$ & 3.4 & 28 & & & & & \\
\hline
\end{tabular}

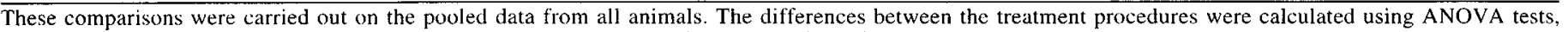
and group comparisons were carried out with the $q$ statistic (see Materials and Methods for details).

measure of reinnervated sensory receptors, Pacinian corpuscles were bilaterally identified and removed from the subcutaneous connective tissues of the finger pads of digit II and III. The digital nerves and Pacinian corpuscles of digit $\mathrm{V}$, innervated by the ulnar nerve, were harvested from both hands and served as controls.

Tissues were post fixed in $2 \%$ glutaraldehyde in $0.1 \mathrm{M}$ phosphate buffer $(\mathrm{pH} 7.2)$ for $24 \mathrm{hr}$ at $4^{\circ} \mathrm{C}$, and then in $2 \%$ osmium tetroxide in $0.1 \mathrm{~m}$ phosphate buffer for $2 \mathrm{hr}$ at room temperature, followed by embedding in Epon 812 resin. Sections were prepared from $2 \mathrm{~cm}$ proximal and distal to the repair sites, the digital nerves, and Pacinian corpuscles. Semithin $(0.1-0.5 \mu \mathrm{m})$ transverse sections were cut from all blocks and stained with toluidine blue. From selected blocks, thin sections (60-150 $\mathrm{nm}$ ) were cut and examined with a Jeol 2000 electron microscope.

Morphometric analysis of myelinated axons. Total numbers of myelinated axon were determined at the light microscope level (Zeiss Axiophot). Video images of the nerve sections were digitized using a Macintosh based image analysis system (NIH IMAGE 1.41 ) and video capture board (Data Translation, Quick Capture). The endoneural cross-sectional area was measured at low power for each nerve trunk. Myelinated axons were counted at high power within a series of adjacent sectors (156 by $120 \mu \mathrm{m}$ ) laid along the longest axis of each fascicle in the nerve cross-section (final image magnification of 1280). Myelinated axons overlapping the left and upper sector lines were excluded. From the axon density and the endoneural cross-sectional area, an estimate of the total number of myelinated axons in each fascicle was calculated. For small fascicles less than $200 \mu \mathrm{m}$ in diameter, all the myelinated axons in the fascicle were counted.

Fiber diameter, axon diameter, and g-ratios were calculated from high power light microscope images with video sample areas of 62.3 by 47.5 $\mu \mathrm{m}$ (final image magnification of 3210). Between 200-400 myelinated axons were analyzed for each nerve sample. Sample areas were made sequentially in a line laid across the widest cross-sectional diameter of each fascicle in the nerve cross-section. The dimensions of an idealized myelinated axon with a circular cross-sectional profile were calculated from the myelin area and the outer perimeter of the myelin sheath to minimize artifacts associated with differential shrinkage of the tissues during histological processing (Karnes et al., 1977; Behse, 1990; Dyck et al., 1992). Myelinated fiber diameter, axon radius, myelin thickness, and g-ratio were individually calculated for each sampled nerve fiber. Summary statistics and frequency distributions were calculated for fiber diameter and g-ratio.

Statistical analyses. Within each experimental group, proximal to distal comparisons were carried out using paired $t$ tests (proximal vs distal). For comparisons across experimental groups, a multifactorial two-way analysis of variance was used to analyze each data set. Significant effects for factors with only two categories are given in the text with the corresponding $p$ values for the analysis of variance without further post hoc comparisons. Multiple comparison tests were performed where the analysis of variance showed significant effects for factors with more than two categories. All morphometric measurements were carried out in a blinded fashion in terms of the source of the tissue section. Interand intrarater reliability was assessed, and measurements between or within observers varied an average of $1.27 \% \pm 0.32 \%$ (mean $\pm \mathrm{SE}$ ).

\section{Results}

\section{Electrophysiological comparisons}

Statistical comparisons of the physiological measures are shown in Table 1. The recovery of the compound motor action potential (CMAP) and compound sensory action potential (CSAP) amplitudes as well as their latencies followed an exponential function. Regression curves reflecting changes in amplitude, latency, and conduction velocity with time after nerve repair, were fitted to the nontransformed data due to heteroscedasticity using the exponential function $Y=a \cdot e^{(b / x 2)}$. An iterative process (SIGMAPLOT, Macintosh IICX) that minimized the square differences from the function was used to define the constants of the equation, where $a=$ the final value of the function, $b=$ the slope of the recovery, and $x=$ the time in days after nerve transection and repair. The total, residual, and regression sums of squares were calculated to define the goodness of fit by means of $F$ and $r^{2}$ values. The differences between the treatment procedures were calculated using ANOVA tests, and multiple group comparisons were carried out with the $q$ statistic (Zar, 1984).

Reinnervation of muscle. The positive control group of direct suture demonstrated a detectable CMAP of the abductor pollicis brevis (APB) at $56 \mathrm{~d}$ postsurgery. There were no significant differences in the average time to detect reinnervation of the APB after repair with nerve guide (mean 61; range 48-70 d) or nerve graft (mean 57; range 54-63 d).

Over time, the CMAP amplitude increased along an S-shaped curve (Fig. 1). Overall, both the nerve guide and graft groups displayed a significantly faster rate of recovery of the CMAP amplitude as indicated by a steeper slope to the fitted curve compared to the direct suture group (Table $1 ; p<0.001$ ). The calculated curves fit the data accurately, with correlation coef- 

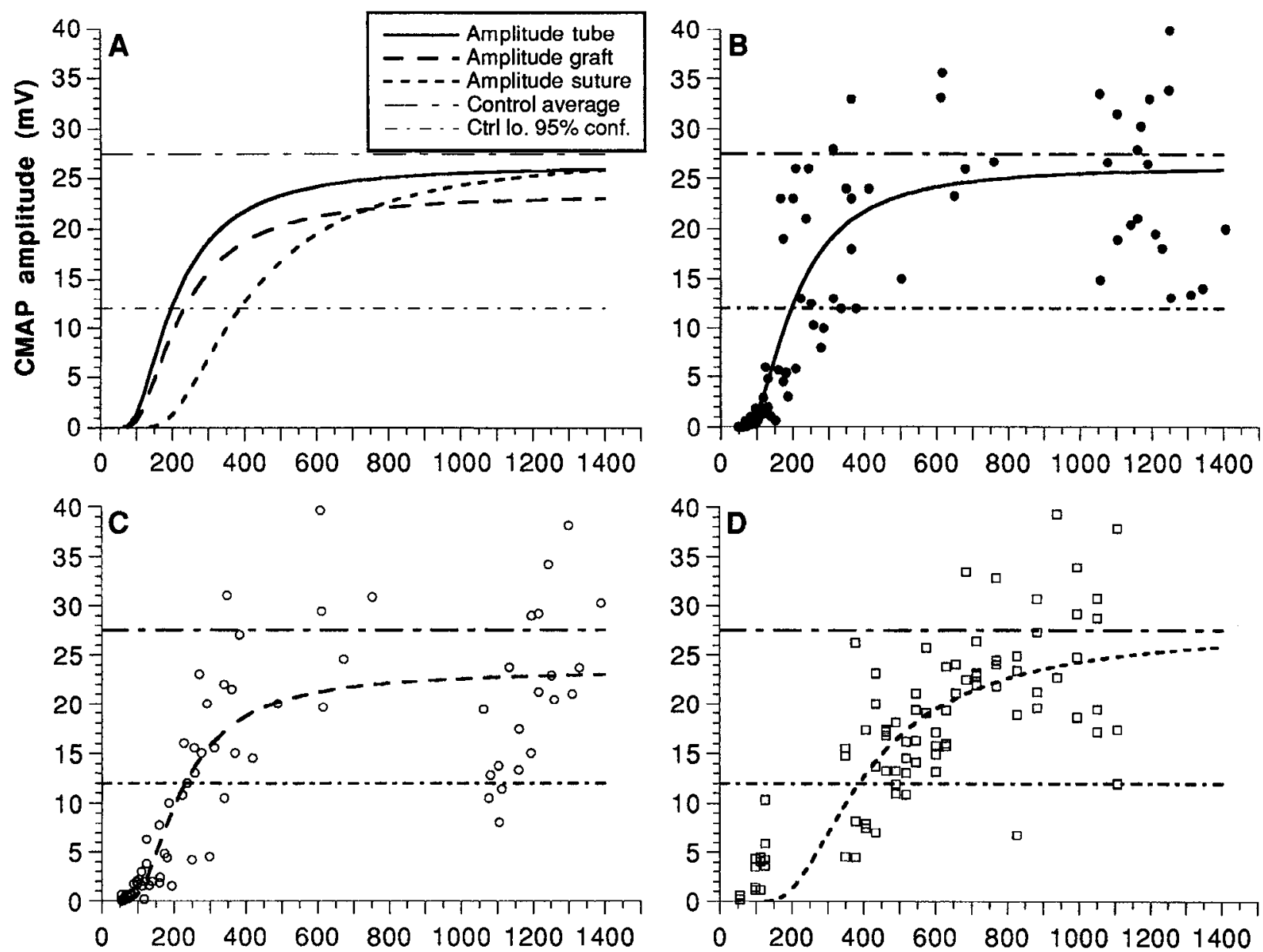

Figure 1. Recovery of the CMAP amplitude following stimulation at the wrist after nerve repair. $A$, Conparison of fitted regression curves; $B$, nerve guide (solid circles); $C$, nerve autograft (open circles); $D$, direct suture (open squares). The upper horizontal dashed line indicates the baseline control average of normal nerves and the lower dash-dot line the lower 95\% confidence limit of the normal control value. Statistical analysis of the slope of the regression curves fitted to the data (see Table 1) indicated that the direct suture group displayed a significantly lower slope function, indicating a slower rate of recovery toward baseline values compared to the other two repair groups.

ficients of $0.85,0.78$, and 0.68 for the nerve guide, graft, and suture groups, respectively.

Measurements taken later than $800 \mathrm{~d}$ after nerve repair were analyzed to estimate the final level of recovery of the CMAP and CSAP amplitudes and latencies (Table 2). By $800 \mathrm{~d}$ the recovery of motor and sensory amplitudes and latencies had reached a stable plateau. It can be seen in Table 2 that the final average CMAP amplitudes among the groups were similar to each other and to normal.

The initial latency of the CMAP for all groups after reinnervation was 15-20 times longer than normal (data not shown). During recovery the latency decreased rapidly at first and then more slowly following at a similar rate for all three groups. There were no statistically significant differences in the slopes of the fitted curves for the three repair groups (Table 1). However, even at extended times following nerve regeneration the latency for the CMAP of all three repair groups was still significantly slower than normal (Table 2).

The motor nerve conduction velocity (MNCV) was also examined from elbow to wrist in the animals which underwent nerve guide or nerve graft repair (data not shown). This section of the nerve included the site of nerve repair. Initially, the MNCV was significantly $(45-50 \%)$ slower than normal nerve for both groups; $67 \pm 1,38 \pm 5$, and $33 \pm 5$, for normal, nerve guide, and nerve graft groups, respectively (values given as mean $\pm \mathrm{SE}$ in $\mathrm{msec}$ ). Both of the repair groups were similar and were significantly different from normal (ANOVA, StudentNeuman Keuls, $p<0.01)$. The later $(341-510$ d) MNCVs increased to $75-90 \%$ of baseline; $62 \pm 3$, and $51 \pm 3$ for nerve guide repair, and nerve graft groups, respectively. These values remained significantly less than the normal control (ANOVA, Student-Neuman Keuls, $p<0.01$ ).

The motor conduction velocity (MNCV) from axilla to elbow was also measured for the same animals during this time period. Although this measurement involved a nerve segment that was completely proximal to the repair site, the MNCV was initially $31-37 \%$ lower in regenerating than in normal nerve; $72 \pm 3$, $50 \pm 5,46 \pm 4$ for the normal, nerve guide, and graft repair groups respectively. The values for the two repair groups were similar and were significantly less than normal (ANOVA, Student-Neuman Keuls, $p<0.01$ ). After 300-400 days, nerve conduction velocity from axilla to elbow was similar after both types of repair $(67 \pm 5,70 \pm 3)$ and no longer differed significantly from normal nerve.

Reinnervation of digital nerves. Electronic averaging of up to 1000 recordings allowed the small sensory action potentials $(0.05-0.1 \mu \mathrm{V})$ to be distinguished from background noise (see also Buchthal and Kuhl, 1979; Krarup et al., 1990). This tech- 
Table 2. Final levels of recovery for the CMAP and CSAP for the three repair groups

A. Comparisons of variables at more than $800 \mathrm{~d}$ after nerve repair

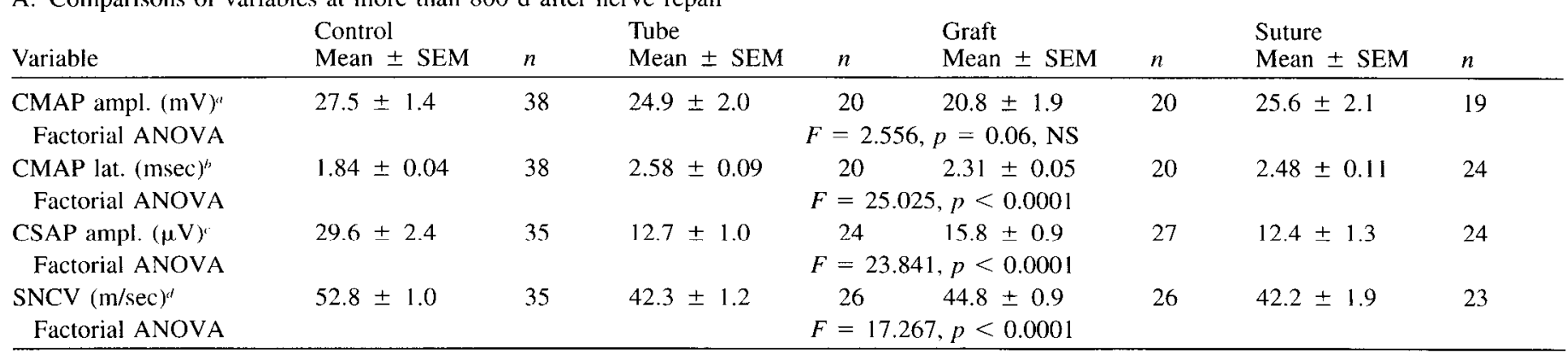

"Amplitude of the compound muscle action potential.

"Latency of the compound muscle action potential.

'Amplitude of the compound sensory action potential.

"Sensory nerve conduction velocity.

B. Scheffe multiple contrast comparison (tests in groups with significant ANOVA)

\begin{tabular}{|c|c|c|c|}
\hline Group comparisons & CSAP amplitude & SNCV & CMAP latency \\
\hline Tube vs graft & NS & NS & NS \\
\hline Tube vs suture & NS & NS & NS \\
\hline Tube vs control & $p<0.01$ & $p<0.01$ & $p<0.01$ \\
\hline Graft vs suture & NS & NS & NS \\
\hline Graft vs control & $p<0.01$ & $p<0.01$ & $p<0.01$ \\
\hline Suture vs control & $p<0.01$ & $p<0.01$ & $p<0.01$ \\
\hline
\end{tabular}

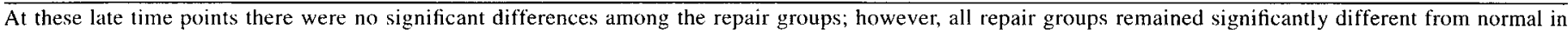
terms of CSAP amplitude, SNCV, and CMAP latency.

nique can evaluate nerve regeneration at carly time points when the amplitude and synchronization of the CSAP is too low to be recorded with surface electrodes (Ballantyne and Campbell, 1973; Tallis et al., 1978). The earliest time at which a sensory nerve action potential (CSAP) evoked by electrical stimulation at the base of digit II could be recorded was similar for all three repair groups (direct suture 56-154 d, nerve guide 83-118 d, or nerve graft 75-98 d). The time to the first evoked CSAP was about $30 \mathrm{~d}$ later than the first responses of an evoked CMAP for all repair groups $(p<0.0001)$.

The amplitude of the CSAP evoked at the base of digit II and recorded at the wrist recovered with a similar S-shaped exponential function as that used to describe the recovery for the CMAP (Fig. 2). The amplitude of the CSAP reached the lower 95\% confidence limit of normal values by about 300-500 d after nerve repair. Similar to the CMAP, both the nerve guide and graft groups displayed significantly $(p<0.05)$ faster rates of recovery of the CSAP amplitude as indicated by a steeper slope of the fitted curve compared to the direct suture group (Table 1).

The final level of recovery of the evoked CSAP amplitude was estimated from measurements taken later than $800 \mathrm{~d}$ after nerve repair (Table 2). The waveform of the CSAP amplitude remained dispersed in shape and recovered to only $40-50 \%$ of normal. At these late time points the average CSAP amplitudes $($ mean $+\mathrm{SF}$. in $\mu \mathrm{V})$ were $12.7+1.0,15.8+0.9$, and $12.4 \pm$ 1.3 for nerve guide, nerve graft, and suture groups respectively (Table 2). There were no significant differences among the repair groups, and all continued to be significantly less than the normal CSAP amplitude of $29.6 \pm 2.4 \mu \mathrm{V}$.

At early stages of regeneration, the maximal sensory nerve conduction velocity (SNCV) along the nerve segment distal to the nerve lesion from the base or tip of digit II to the wrist was markedly slow. The SNCV gradually increased and reached the lower $95 \%$ confidence limit of normal about 400-500 d after repair (data not shown). There were no differences in the slopes of the recovery curves for the SNCV among repair groups (Table 1), and even at extended times following nerve regeneration the SNCV of all three repair groups remained significantly slower than normal (Table 2).

The sensory nerve conduction velocities (SNCV) were examined along the forearm (wrist to elbow) and the upper arm (elbow to axilla) for the nerve guide and nerve graft groups at initial $(<341 \mathrm{~d})$ and later $(>341-510 \mathrm{~d})$ stages of regeneration. The initial SNCV along the segment from wrist to elbow across the repair site was similar after the two types of nerve repair and was approximately $50 \%$ of that in normal nerve (normal $=$ $82 \pm 2 \mathrm{~m} / \mathrm{sec}$ ). Both of the repair groups were significantly different from normal (Table 2), but not different from each other. Although there were significant increases in the SNCV along this same nerve segment at the later time points to about $75 \%$ of normal values, they remained significantly slower than normal. Completely proximal to the repair site, the initial SNCV from elbow to axilla was about $50 \%$ of normal control (normal $=90 \pm 4 \mathrm{~m} / \mathrm{sec}$ ). Both of the repair groups significantly increased their SNCV along this same nerve segment to about $80 \%$ of normal, but remained significantly slower than normal (Table 2).

Recovery of evoked responses from finger pads. In the nerve guide and nerve graft repair groups sensory nerve regeneration to the tip of digit II was investigated by evoking a CSAP by electrical and tactile stimuli. Electrical stimulation was used to evoke a response from all of the regenerated nerve fibers and the tactile stimulus to evoke a response only from axons which 

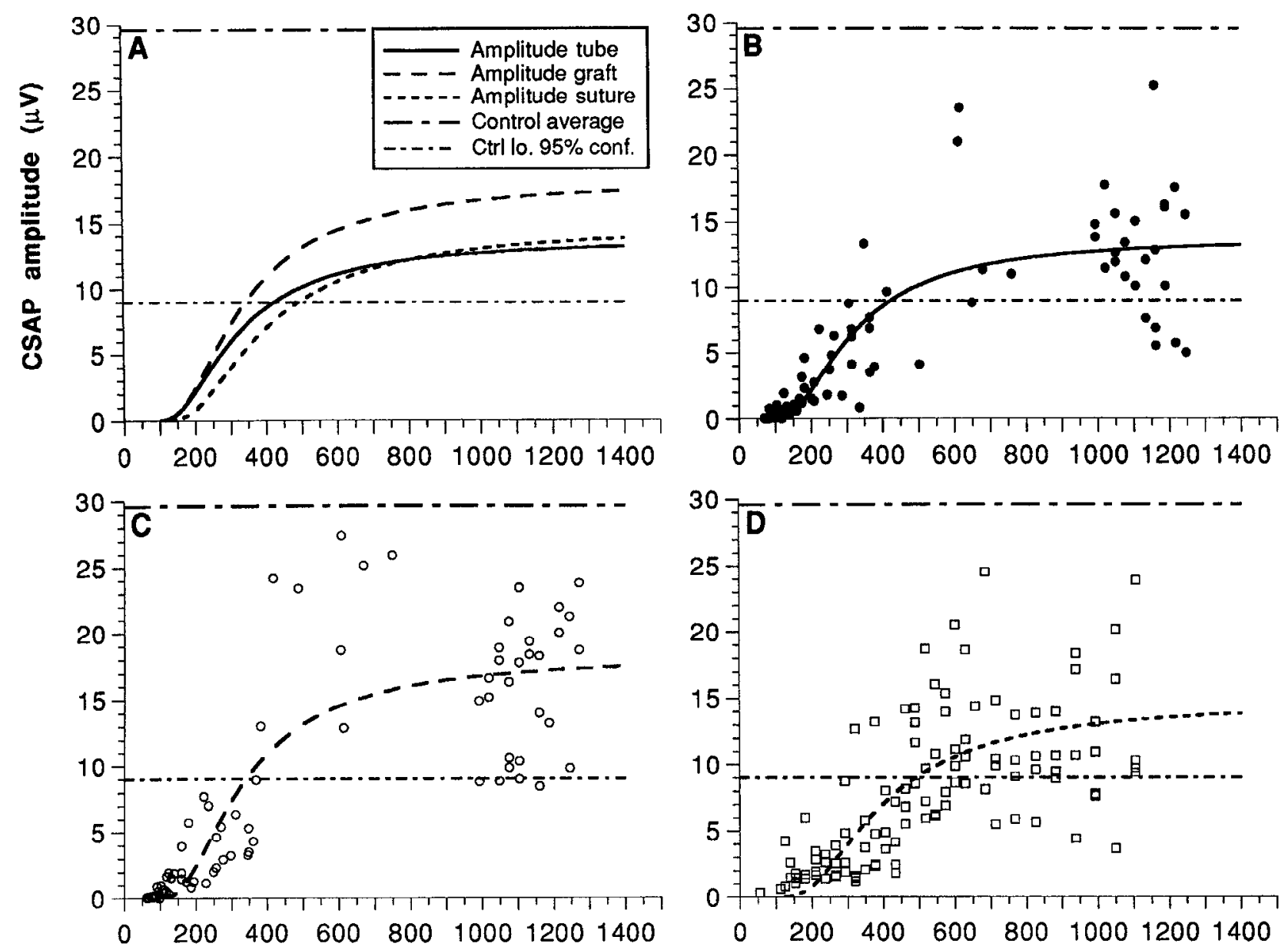

Figure 2. Recovery of the CSAP amplitude after nerve repair. A, Comparison of fitted regression curves; $B$, nerve guide (solid circles); $C$, nerve autograft (open circles); $D$, direct suture (open squares). The nerve was stimulated at the base of digit II and the CSAP was recorded at the wrist. The upper horizontal dashed line indicates the baseline control average of normal nerves and the lower dash-dot line the lower $95 \%$ confidence limit of the normal control value. Statistical analysis of the slope of the fitted line to the data (see Table 1) indicated that the direct suture group displayed a significantly lower slope function, indicating a slower rate of recovery toward baseline values compared to the other two repair groups.

had reinnervated touch receptors in the finger tip. These measurements were carried out for approximately the first year following nerve repair.

The average time to the first electrically evoked CSAP from the tip of digit II was $45 \mathrm{~d}$ more delayed than the time at which a CSAP was evoked from the base of the digit (paired $t$ test, $p$ $<0.001$ ), this delay was not significantly different after nerve guide repair (104-209 d) versus graft repair (103-131 d).

The recovery of the electrically evoked CS $\triangle \mathrm{P}$ amplitude from the tip of digit II to wrist followed a similar S-shaped function as that used to describe the recovery of the CSAP from the base of the digit (data not shown). Approximately 1 year after surgery, the amplitude of the electrically evoked CSAP from the tip of digit II was similar for both repair groups $(1.9 \pm 0.4 \mu \mathrm{V}$, nerve guide; $2.7 \pm 0.9 \mu \mathrm{V}$, nerve graft), and both remained significantly lower than normal (12.9 $\pm 1.1 \mu \mathrm{V}$; ANOVA, Student Neuman Keuls, $p<0.001)$.

Tactile evoked response. The normal pattern of a tactile evoked CSAP is shown in Figure $3 C$. A response could be recorded in all of the nerves repaired by either nerve guide or nerve graft. To verify that the evoked tactile response was elicited via the receptors in the digit, the pulpa was infiltrated with $2 \%$ lidocaine. The local anesthetic completely blocked the tactile response indicating that the sensory receptors being stimulated were restricted within the finger tip. Both the CSAP evoked by electrical stimulation or by the defined tactile stimulation disappeared completely within 4-5 min after local anesthesia (Fig. $3 D, E)$, and subsequently recovered.

Tactile evoked responses were recorded from 100 to $400 \mathrm{~d}$ after nerve repair. There was only a slight increase in amplitude of the tactile response over this time period. Therefore, responses were pooled for each group over time. The pooled amplitude of the tactile evoked response was similar after nerve guide repair $(0.53 \pm 0.08 \mu \mathrm{V} ; n=16)$ and nerve graft repair $(0.54 \pm 0.12 \mu \mathrm{V} ; n=12)$, and both were significantly less than normal $(1.2 \pm 0.1 \mu \mathrm{V} ; p<0.01)$

The pooled latency of the tactile evoked sensory response at $300-400 \mathrm{~d}$ after surgery was $3.2 \pm 0.2 \mathrm{~m} / \mathrm{sec}$ in repaired nerve which was about one and a half times longer than the control value of $2.0 \pm 0.1 \mathrm{~m} / \mathrm{scc}(t$ test, $p<0.001)$. In order to further evaluate the localization of this delay, the latency difference between the tactile and the electrically evoked CSAP was calculated to estimate the "receptor-delay," or the time taken to convert the tactile stimulus to an electrically detectable nerve response. In regenerated nerve the latency difference was 0.79 $\pm 0.1 \mathrm{msec}$ which was three times longer than the normal value of $0.26 \pm 0.07 \mathrm{msec}(t$ test, $p<0.001$ ).

Electrophysiological findings in two nerves with a $15 \mathrm{~mm}$ 


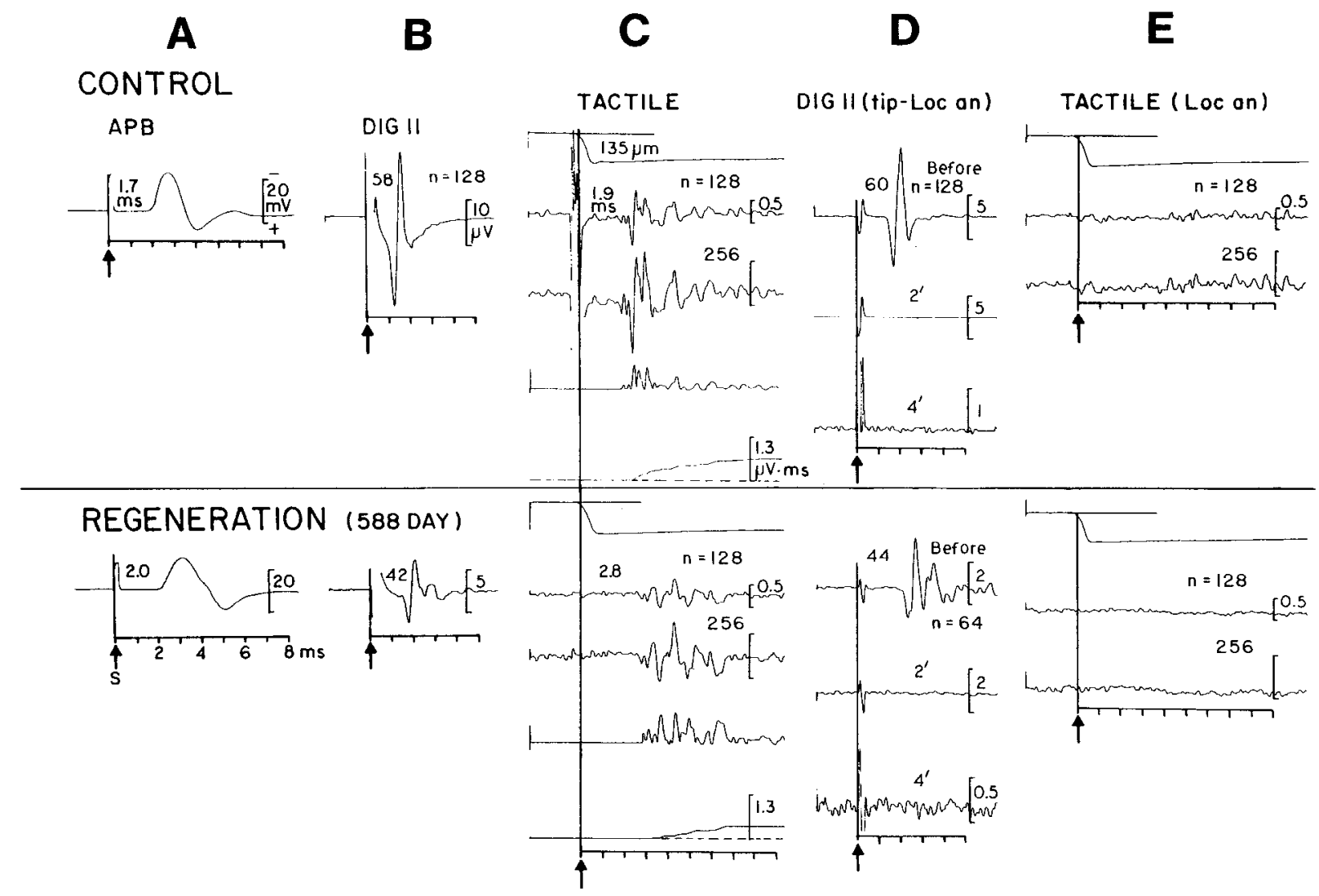

Figure 3. Typical waveform recordings are shown of motor and sensory responses in order to illustrate differences between control (above) and regenerated (below) median nerve. The regenerated nerve responses are from a nerve repaired with a collagen nerve guide $588 \mathrm{~d}$ postsurgery. $A$, The CMAPs are shown evoked by electrical stimulation at the wrist and recorded from the abductor pollicis brevis muscle (APB). The latency of the response is indicated above the traces ( 1.7 vs 2.0 ; for normal and regenerated nerve, respectively). $B$, The CSAPs are shown evoked by electrical stimulation at the base of digit II and recorded from the median nerve at the wrist ( $n=$ number of averaged responses). The conduction velocity is indicated above the traces ( 58 vs 42 , respectively). $C$, The CSAPs are shown evoked by tactile stimulation (see Materials and Methods) at the tip of digit II and recorded from the median nerve at the wrist. The uppermost trace shows the initial portion of a single tactile stimulus. The two following traces show the averaged responses to two sets of stimuli $(n=128$ and 256) to confirm the response. The latency of the response is indicated above the trace (1.9 vs $2.8 \mathrm{msec}$, respectively). The next to lowermost trace shows the rectified response and the lowermost trace the integrated response. $D$, The CSAPs are shown evoked by electrical stimulation at the tip of digit II and recorded from the median nerve at the wrist before, and their disappearance after, local anesthesia of digital nerves. $E$, During the same recording session the tactile responses following local anesthesia of digital nerves of digit II are also abolished.

nerve gap repair. In one ulnar and one median nerve a deficit of $15 \mathrm{~mm}$ was repaired with a collagen nerve guide. Evoked CMAPs were followed in the abductor digiti quinti (ADQ) (ulnar nerve) and abductor pollicis brevis (APB) (median nerve) muscles respectively (data not shown). These nerves had previously been repaired with a polylactate nerve guide to bridge a $4 \mathrm{~mm}$ nerve gap. All of the physiological measurements in these two nerves were compared to the previous baseline levels reached by the $4 \mathrm{~mm}$ nerve repair at approximately 2 years. The first detectable CMAPs were recorded 89 (ADQ muscle) and 104 (APB muscle) d after nerve repair. As expected, the time to initial reinnervation was delayed after repair of the $15 \mathrm{~mm}$ long nerve gap compared to the 55-60 d for the $5 \mathrm{~mm}$ nerve gap. The CMAP amplitudes increased rapidly from approximately $200 \mathrm{~d}$ to $700 \mathrm{~d}$ and eventually reached the previous haseline levels for the median innervated APB $(15.5 \mathrm{mV})$ and ulnar innervated ADQ $(9.5 \mathrm{mV})$. The CMAP latency took longer to return toward baseline levels compared to the $5 \mathrm{~mm}$ nerve gap repair, and remained significantly longer than normal for the entire observation period.

The CSAP amplitudes recovered slowly for approximately the first $400 \mathrm{~d}$ and then more rapidly until the end of the study (approximately 3 years). By the end of the study the CSAP amplitudes had surpassed the previous levels achieved following polylactate nerve guide repair. The median nerve increased from $5.7 \mu \mathrm{V}$ to $7.5 \mu \mathrm{V}$, and the ulnar nerve increased from $4.5 \mu \mathrm{V}$ to $8.2 \mu \mathrm{V}$. Response to a tactile stimulus was recorded after stimulation of the digit by $300 \mathrm{~d}$ following nerve repair. This tactile evoked CSAP had an amplitude similar to that found in the $5 \mathrm{~mm}$ nerve gap repair animals $(0.4 \mu \mathrm{V}$ for $15 \mathrm{~mm}$ and 0.6 $\mu \mathrm{V}$ for $5 \mathrm{~mm}$ ), but the latency $(4.1 \mathrm{msec})$ was about $30 \%$ longer than after the $5 \mathrm{~mm}$ repair $(3.2 \mathrm{msec})$ and about $100 \%$ longer than normal $(2.0 \mathrm{msec})$.

\section{Histological morphometrics}

The median nerve grafts were identified by gross examination at the terminal dissection by the slight swelling of the nerve trunk at each suture line, in a few cases the microsutures used in the anastomosis were also present. Upon harvesting the collagen nerve guide repair site there was no indication of the suture line swelling observed in the grafts, the nerve guides were completely absent and the lesion site could occasionally be iden- 

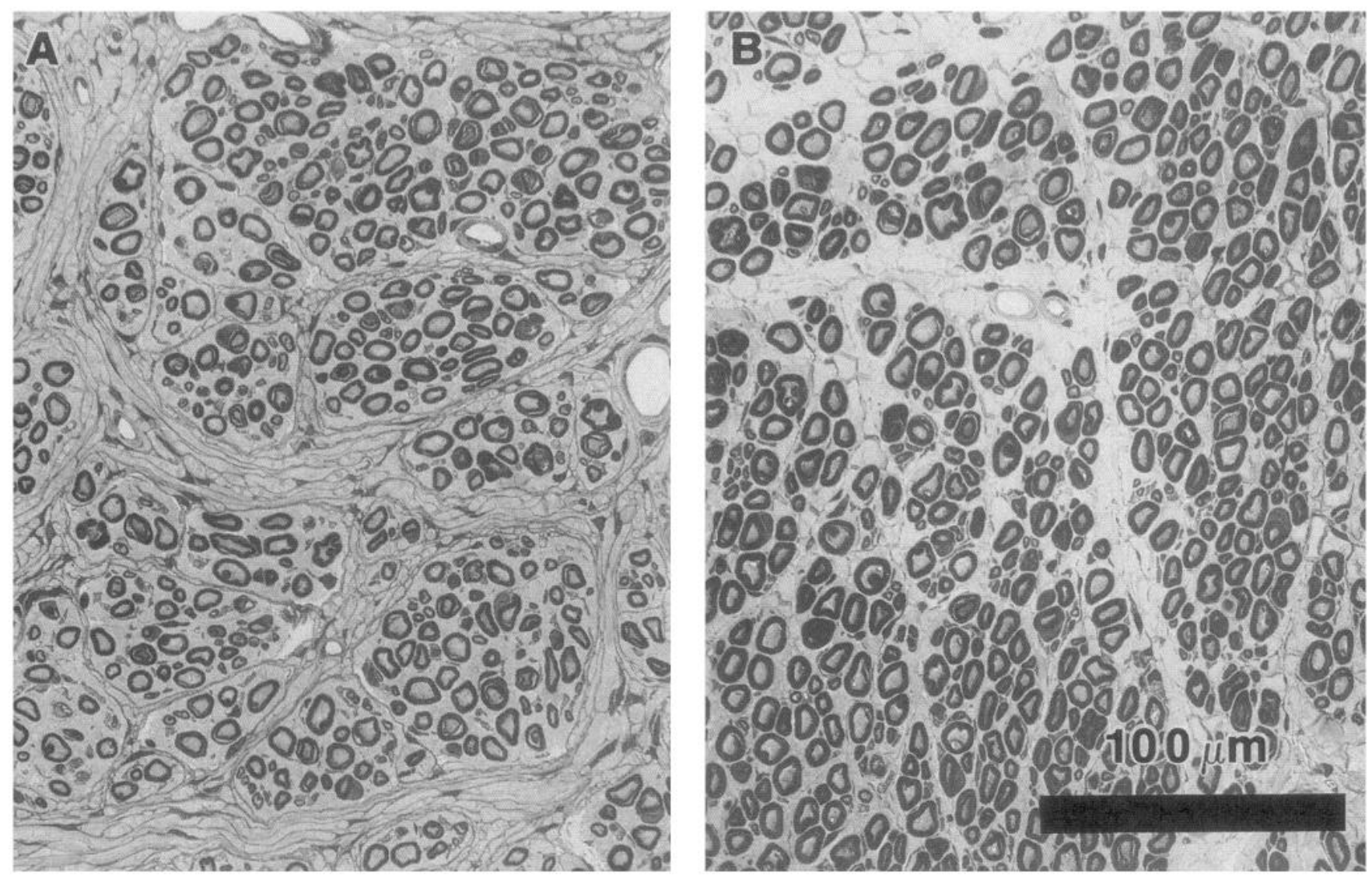

Figure 4. Histology of the repair site. Shown in this figure are representative light micrographs of transverse sections of the regenerated nerve from a collagen nerve guide and nerve graft repaired median nerve. A, High power cross-sectional view of the endoneurium at the mid-point of a nerve cable regenerated through a collagen nerve guide. Note the absence of scar tissue and many well-myelinated axons. $B$, View of the endoneurium at the midpoint of a median nerve graft. Note the similarity in appearance of the endoneural area to that shown in $A$.

tified by the presence of microsutures. When examined grossly, the regenerated tissue resulting from the nerve guide repairs had the opalescent quality of normal nerve trunk, the repair site was examined under the dissecting microscope and could be identified by the absence of the normal multifascicular structure of the median nerve trunk. Adhesion, compression, or fibrotic reaction to the nerve guides was not observed.

There were no notable histological differences in the endoneural tissue between the nerve graft and nerve guide samples (Fig. 4). The total average fascicular area in the normal controls at the same levels as the median nerve repairs was $0.760 \pm 0.05$ $\mathrm{mm}^{2}$ (mean $\pm \mathrm{SEM}$ ), following nerve graft repair it was 0.693 $\pm 0.13 \mathrm{~mm}^{2}$ proximal to the lesion and $0.692 \pm 0.10 \mathrm{~mm}^{2}$ distally, and following nerve guide repair it was $0.62 \pm 0.09$ proximal to the lesion and $0.86 \pm 0.13 \mathrm{~mm}^{2}$ distally.

Myelinated axon population. In both the nerve guide and nerve graft repair groups there were similar significant increases in the total number of myelinated axons found distal to the lesion compared to their respective proximal values or to normal controls $(p<0.05$; Fig. $5 A)$. There was also a marked increase in the density of myelinated fibers distal to the lesion compared to proximal values or to normal controls (Fig. $5 B$ ). The increase in axonal density from proximal to distal was statistically significant across repair groups (Anova, $p<0.001$ ), but a post hoc paired $t$ test within each group found that the increase reached statistically significant levels only within the nerve graft repair group $(p<0.005$; Fig. $5 B$ ). Both groups displayed significantly greater densities than the normal controls (ANOVA, StudentNeuman-Keuls, $p<0.05$ ).

Proximal to the nerve lesions the average fiber diameters were similar to control values of $7.81 \pm 0.60 \mu \mathrm{m}$ (nerve guide $=$ $8.29 \pm 0.38 \mu \mathrm{m}$, and nerve graft $=8.35 \pm 0.64 \mu \mathrm{m})$. Distally, there were significant proximal to distal reductions in average fiber diameter for both nerve guide and graft repair (Fig. $5 C ; p$ $<0.05$, paired $t$ tests).

Distribution of fiber diameters and g-ratios. The frequency distribution of fiber diameters in the normal median nerve at the wrist and $2 \mathrm{~cm}$ proximal to the repair sites have normal bimodal distributions over a range of $1-19 \mu \mathrm{m}$ (Fig. 6A). The major peak in the distribution is evident at $3 \mu \mathrm{m}$, and a minor peak occurs at $12-13 \mu \mathrm{m}$. Distal to the repair sites, the bimodal characteristic of frequency distributions were less distinct with a ranges of 1$18 \mu \mathrm{m}$ (Fig. 6A,B). The major peaks in the regenerated fiber frequency distributions were at $4 \mu \mathrm{m}$, and although not immediately obvious, small minor peaks were also present at $7 \mu \mathrm{m}$ for nerve guide and $8 \mu \mathrm{m}$ for graft repair.

The g-ratio quotient describes the relationship between axon caliber and myelinated fiber caliber for myelinated axons ( $\mathrm{g}$-ratio $=$ axon diameter/myelinated fiber diameter). The normal control median nerve has a g-ratio range of $0.45-0.98$. Shown in Figure $6 D-F$ are scatterplots of g-ratio versus fiber diameters. Two distinct clusters can be identified within the distribution of data points for the normal control g-ratio values (Fig. $6 D$ ). These two clusters correspond to the peaks in the fiber diameter frequency 
A.
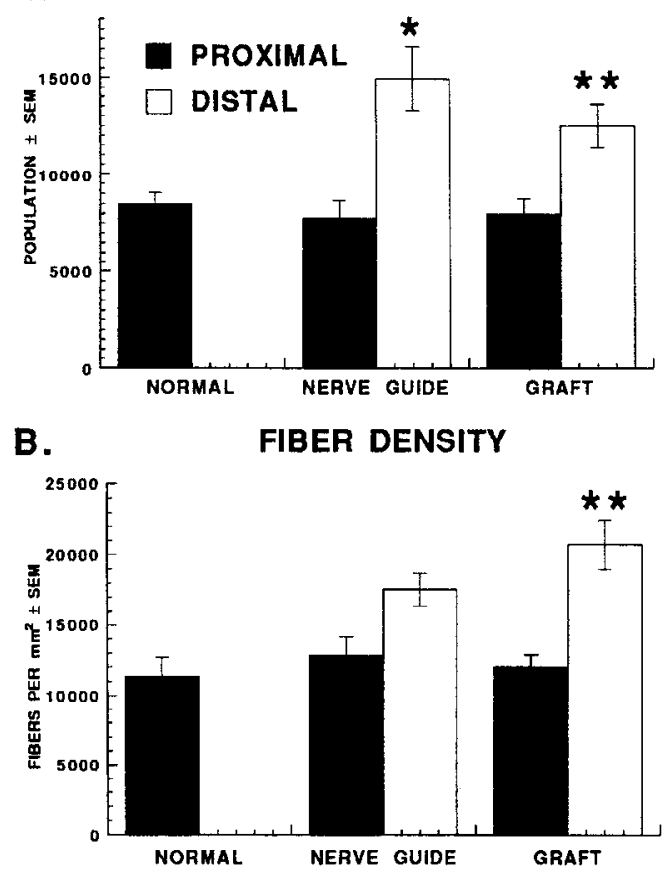

C.

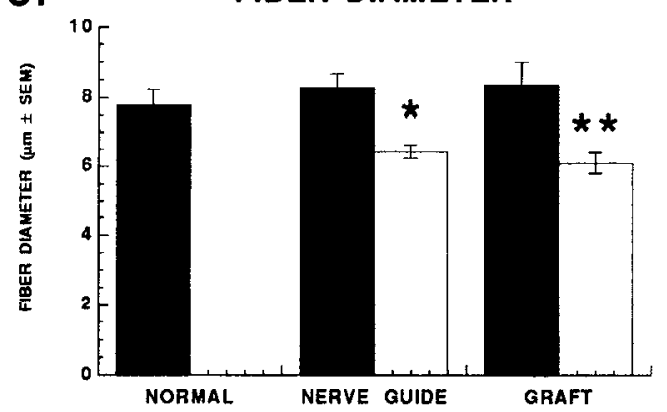

Figure 5. Quantitative assessments of the regenerated myelinated axons. Asterisks denote statistical differences between the proximal and distal values within each group $\left(^{*}, p<0.05 ; * *, p<0.005\right.$, paired $t$ tests). Error bars represent the SEM. A, The estimated total populations of myelinated axons in the proximal and distal nerve trunks are indicated for the two repair groups compared to normal median nerve. Both repair groups had significantly more myelinated axons in the distal nerve trunks compared to proximal values or to control values. $B$, The estimated densities of regenerated myelinated axons are indicated for both repair groups. Both repair groups had significantly greater than normal values, and the nerve graft group displayed significant differences between proximal and distal values. $C$, The average diameters for myelinated axons in the proximal and distal nerve trunks are indicated for each repair group. Both repair groups had significantly smaller fiber diameters compared to normal values, or compared to their own proximal valucs.

distribution derived from the same group of fibers (Fig. $6 A$ ). One cluster, of smaller diameter fibers $(2-6 \mu \mathrm{m})$, is located around a marginally higher g-ratio value than the cluster corresponding to the $12-13 \mu \mathrm{m}$ peak of the fiber diameter frequency distribution. The overall reduction in g-ratio values with increasing fiber diameter is demonstrated by the negative slope of the simple regression line through the data.

The scatterplots of g-ratio versus fiber diameter for the axon populations proximal to the nerve lesions were less focused compared to normal with an increased range of g-ratio values (data not shown). Despite the general increase in the dispersion of the g-ratio values over the whole range of fiber diameters, distinct clusters were still present proximal to the lesion in both the nerve guide and graft distributions. Retrograde effects of the nerve lesion are responsible for the slight changes in these distributions, and are also responsible for the subtle alterations in electrophysiological activity recorded in proximal nerve (see Discussion).

Distal to the repair sites, the scatterplot distributions of g-ratio versus fiber diameter are shifted to higher g-ratio values and lower fiber diameters, which is reflected as a change in the slope of the regression lines from negative (Fig. $6 D$ ) to positive (Fig. $6 E, F)$. The increase in the average g-ratio value to $0.78 \pm 0.01$ distal to the nerve guide repair was significantly higher than normal controls of $0.67 \pm 0.01$ (Student-Neuman-Keuls, $p<$ 0.05 ).

The three-dimensional surface plots of the frequency distribution of the relationship between g-ratio and fiber diameter were determined by transforming the data into a matrix with a g-ratio range from 0.3 to 1.0 (bin sizes of 0.05 ) and a fiber diameter range from zero to $20 \mu \mathrm{m}(1.0 \mu \mathrm{m}$ bins). Each cell of the matrix contained the number of occurrences of nerve fibers within the axon population that have the characteristics defined by the g-ratio and fiber diameter coordinates for that cell (see Fig. 7). In the normal controls the two clusters previously identified in the distribution of the g-ratio versus fiber diameter scatterplots are now graphically represented as two prominent peaks using this analysis method (e.g., compare Figs. $6 D, 7 A$ ). This method clearly reveals the presence of two peaks in the data distributions from the distal repaired nerves that were not seen in the scatterplots (e.g., compare Figs. $6 E, F ; 7 B, C$ ), and were only hinted at in the fiber diameter histograms (Fig. $6 B, C$ ).

Digital nerves (data not shown). The frequency distribution of fiher diameters in the normal digital nerve was similar in shape to the bimodal fiber diameter distribution found in normal median nerve, but with a much reduced range $(2-13 \mu \mathrm{m})$ and a smaller average size $(6.83 \pm 0.14 \mu \mathrm{m})$. Regenerated digital nerves had a reduction in the range of the fiber diameter distribution $(1-11 \mu \mathrm{m})$. However, there was a clear recovery of the bimodal fiber diameter frequency distribution. The average fiber diameters distal to the nerve repairs were $5.43 \pm 0.1 \mu \mathrm{m}$ for the nerve guide group and $6.42 \pm 0.13 \mu \mathrm{m}$ for the nerve graft group. The average g-ratio in both nerve guide $(0.68 \pm 0.004)$ and nerve graft groups $(0.65 \pm 0.004)$ were reduced from normal $(0.71 \pm 0.004)$. A three-dimensional surface plot was constructed for the relationship between g-ratio and fiber diameter as described above. Again the bimodal nature of the distribution was seen in normal nerve, and the return of this bimodal distribution was clearly seen in both of the regenerated digital nerve samples.

Pacinian corpuscles. The Pacinian corpuscles from control digits were innervated by both single and branched axon terminals (Fig. 8A). Axon branches were always limited to the central canal of the Pacinian corpuscle inner core and each branch was a focus of organization for a concentric series of condensing lamellae. Pacinian corpuscles recovered from the base of digits II and III following repair of the median nerve by either nerve guide or nerve graft showed a wide range of reinnervation of their inner cores. None of the regenerated axons found within the Pacinian corpuscles fully occupied the central canal that had been vacated by the original innervating fibers. In some, the regenerated axons were interspersed between the lamella folds of the inner core. These axons were devoid of 

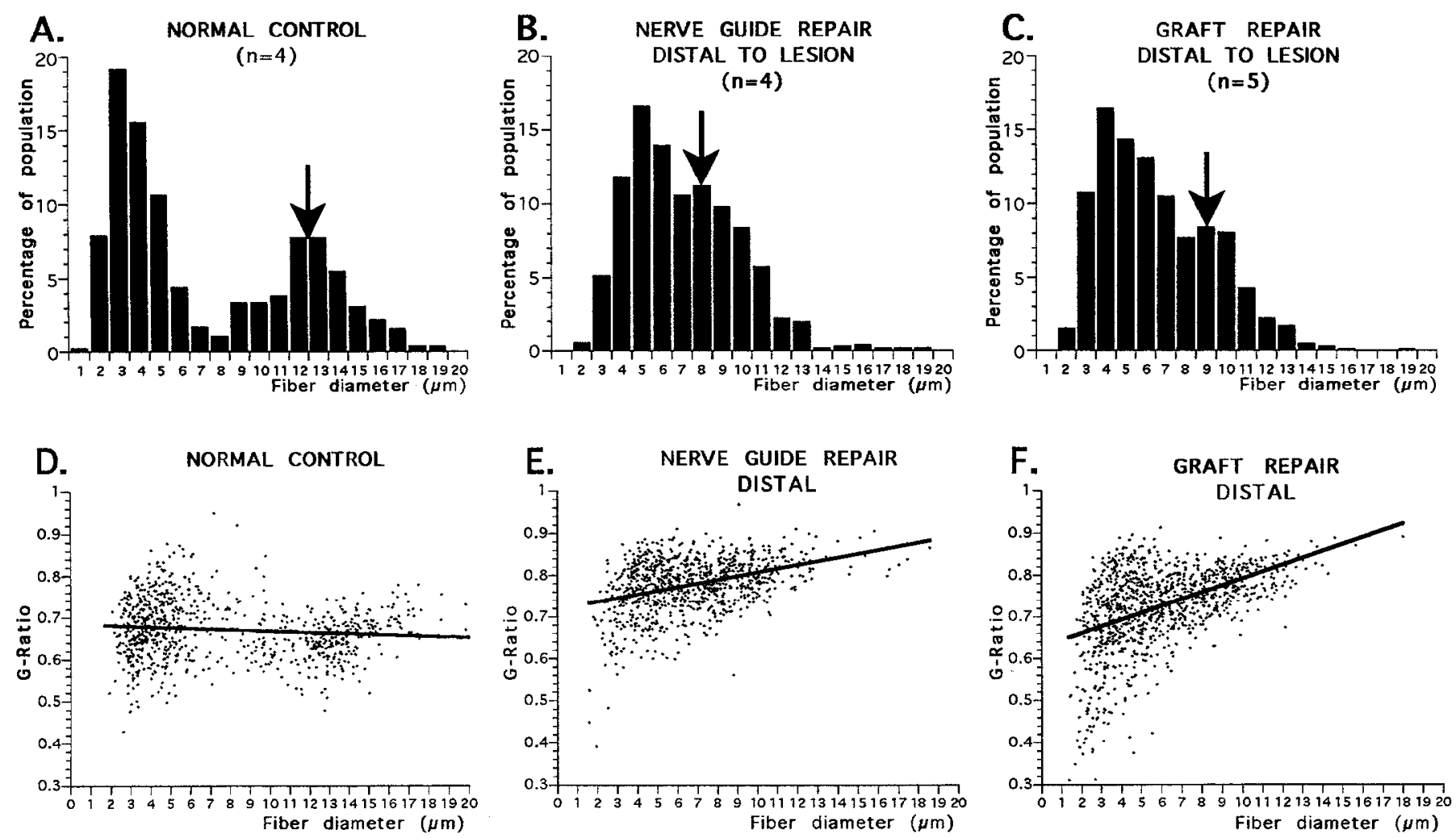

Figure 6. A-C, Frequency distributions for the sizes of myelinated axons in the nerve trunks distal to the lesion compared to normal nerve. A, The distribution of fiber sizes in the control nerves is distinctly bimodal with the major peak at approximately 3-4 $\mu$ mI and the ininor peak indicated by an arrow at $12-13 \mu \mathrm{m}$. Similar distributions occur for myelinated axons $2 \mathrm{~cm}$ proximal to the repair sites in both repair groups (not shown). $B$ and $C$, The regenerated fiber diameter frequency distributions in the distal nerve trunks are not as distinctly bimodal. However, major peaks in the distribution occur at 4-5 $\mu \mathrm{m}$, and minor peaks are discernable at $7 \mu \mathrm{m}$ and $8 \mu \mathrm{m}$ (arrows) for the nerve guide and nerve gratt repair groups, respectively. $D-F$, Scatterplots of g-ratio versus fiber diameter for the myelinated axons in the distal nerve trunks of repaired nerve compared to normal control. The line through the scatterplots is a simple regression line fit to the data. $D$, The normal nerve shows two clear clusters which relate to the major and minor peaks of the frequency distributions of fiber size shown in $A$. Note that the regression line has a slightly negative slope. $E$ and $F$, The scatterplots for myelinated axons found $2 \mathrm{~cm}$ distal to the repair sites for both repair groups are markedly different from those found proximally or in normal nerve. The regression line has changed from a slightly negative slope to a positive slope. This change indicates that unlike normal nerve, the larger regenerated axons distal to the lesion have relatively thinner myelin sheaths compared to smaller axons. There are also increases in the g-ratio ranges, especially for the nerve graft repair group $(E)$. The two focused clusters which were evident in normal nerve and proximal to the repair site have also largely disappeared.

Schwann cell basal lamina and were filled with mitochondria suggesting that they were physiologically functional (Fig. 8B). In others, normally myelinated axons were found interspersed within the lamellae of both the inner core and the outer envelope of the corpuscle (Fig. 8C). Approximately $50 \%$ of the Pacinian corpuscles were not reinnervated. In many cases the central canal of the inner core remained intact (Fig. 8D), while in others the canal had collapsed with the lamella folds of the inner core appearing diffuse and ill defined.

Fifteen millimeter nerve guides (data not shown). Observations from the one median nerve $1077 \mathrm{~d}$ after rerepair showed a minor reduction in the range of the bimodal fiber diameter distribution proximal to the lesion $(1-16 \mu \mathrm{m})$ compared to the normal controls $(1-19 \mu \mathrm{m})$. The average fiber diameter proximal to the repair $(6.66 \pm 0.29 \mu \mathrm{m})$ was also reduced compared to normal $(7.81 \pm 0.6 \mu \mathrm{m})$. Distal to the lesion the fiber diameter distribution was unimodal with a range of $1-9 \mu \mathrm{m}$ and an average diameter of $4.85 \pm 0.12 \mu \mathrm{m}$. The range and average fiber diameters following the $15 \mathrm{~mm}$ long nerve guide repair are smaller than any of the results from the $5 \mathrm{~mm}$ nerve guide or nerve graft repairs. The g-ratio proximal and distal to the lesion was approximately $0.69 \pm 0.01$ which is within the range for normal nerve. The total number of distal myelinated axons was 12,297 ( $136 \%$ increase compared to proximal), which is equivalent to the number of axons regenerating into the distal stump following nerve guide repairs of the $5 \mathrm{~mm}$ median nerve deficit.

In the one $15 \mathrm{~mm}$ ulnar nerve repair, the proximal bimodal distribution of fiber diameters had a range of $1-11 \mu \mathrm{m}$ and an average size of $4.4 \pm 0.16 \mu \mathrm{m}$. The fiber diameter distribution distal to the repair site had a narrower range of $1-8 \mu \mathrm{m}$ and an average size of $3.3 \pm 0.1 \mu \mathrm{m}$. The g-ratio proximal to the nerve guide was $0.44 \pm 0.008$ and distal to the nerve guide $0.56 \pm$ 0.007 . The myelinated axon population distal to the ulnar nerve $15 \mathrm{~mm}$ long nerve guide repair was 13,374. This total number of myelinated axons represents a $92 \%$ increase in the number of myelinated axons proximal to the lesion.

\section{Discussion}

It is well known that in human and nonhuman primates peripheral nerve regeneration and maturation after severe trauma may take place over a period of several years (Sunderland, 1991). The three and a half years of serial electrophysiological assessments in this study provided information on a longitudinal basis concerning both the rate of nerve regeneration and maturation 

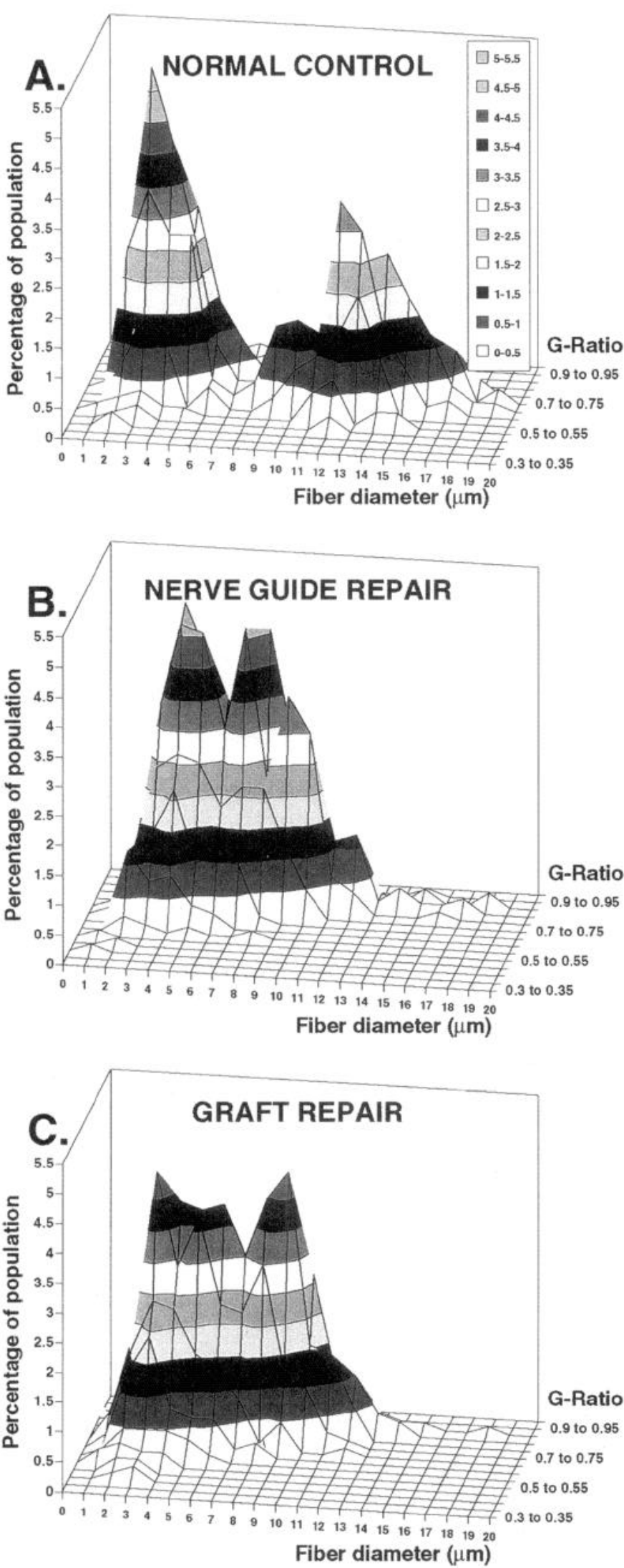

Figure 7. Three-dimensional plots representing the combined relationship between the frequency distributions of fiber diameter and g-ratio. The grids are graphical representations of the matrices derived from the fiber diameter versus g-ratio data; thus, the topography defines the relative density of the individual data points in the corresponding scatter- as well as the final stable levels of recovery. The electrophysiological studies represent the most extensive serial data ever reported for nonhuman primate peripheral nerve regeneration. Morphometric analyses at the completion of the electrophysiological assessments confirmed that nerve regeneration was similar after nerve guide or graft repair of a $5 \mathrm{~mm}$ deficit.

\section{Serial electrophysiological comparisons}

The major electrophysiological findings were that median nerves repaired by either nerve graft or nerve guide displayed a significantly faster recovery rate for the amplitudes of the compound motor action potentials (CMAP) and the compound sensory action potentials (CSAP) compared to nerves repaired by direct suture (see Table 1, Figs. 1, 2). Despite the differences in the recovery rates, all physiological measures eventually recovered to similar stable values which remained significantly different from normal (see Table 2).

Reinnervation of the thenar muscles by the median nerve occurred within 50-70 d, over a distance of about 30-50 mm after all three types of repair. Similarly, a CSAP could be evoked from the base of digit II 56-154 d after nerve repair. There were no significant differences among the groups in terms of the time to the first detectable responses. The delay in reinnervation suggests axonal growth rates distal to the nerve lesion of $0.5-1$ $\mathrm{mm} / \mathrm{d}$ for both of the repair procedures. This is consistent with previous studies in humans for sensory and motor axons (Buchthal and Kuhl, 1979; Sunderland, 1991).

At early time points of regeneration $(<300 \mathrm{~d})$ the latency of the CMAP was 15-20 times normal and the sensory nerve conduction velocity was only $10-20 \%$ of normal (data not shown). This reduction in nerve conduction velocity is similar to that described previously in humans (Hodes et al., 1948) and experimental animals (Krarup and Gilliatt, 1985) and is due to the thin myelin sheath and small diameter of the regenerated fibers (see Morphological comparisons below and Berry et al., 1944; Erlanger and Schoepfle, 1946; Krarup et al., 1988). The conduction properties of the regenerated nerve fibers increased rapidly during maturation, as a result of increases in axon caliber and myelination.

The motor nerve conduction velocity (MNCV) and sensory nerve conduction velocity ( $\mathrm{SNCV}$ ) proximal to the transection site, between elbow and axilla was reduced by $30-40 \%$ during early regeneration and gradually recovered incompletely after both nerve graft and nerve guide repair (data not shown). The reduction in conduction velocity in the proximal nerve trunk has been reported to be caused by retrograde atrophy proximal to a

$\leftarrow$

plots from Figure $6 D-F$. The contours are incremented at intervals of $0.5 \%$ of the total number of observations (see scale in $C$ ). $A$, The normal nerve has two distinctly separate peaks of myelinated axons as defined by their fiber diameter and g-ratio. The two groups correspond directly to the peaks of the myelinated axon fiber diameter distribution and to the foci of the fiber diameter versus g-ratio scatterplot for the same data (compare to Fig. 6A). $B$ and $C$, The three-dimensional plots for the regenerated axons found $2 \mathrm{~cm}$ distal to the nerve guide and nerve graft repairs are markedly different from the normal nerve. The two separate groups found in the normal nerve have been replaced by distributions encompassed by single $1-2 \%$ and $2-3 \%$ contours. However, both of the distributions have two distinct peaks which demonstrate the partial return of the bimodal fiber diameter distribution that could not be determined from the corresponding fiber diameter versus g-ratio scatterplots (Fig. $6 E, F$ ) and was only marginally indicated from the fiber diameter frequency distributions (Fig. $6 B, C$ ). 

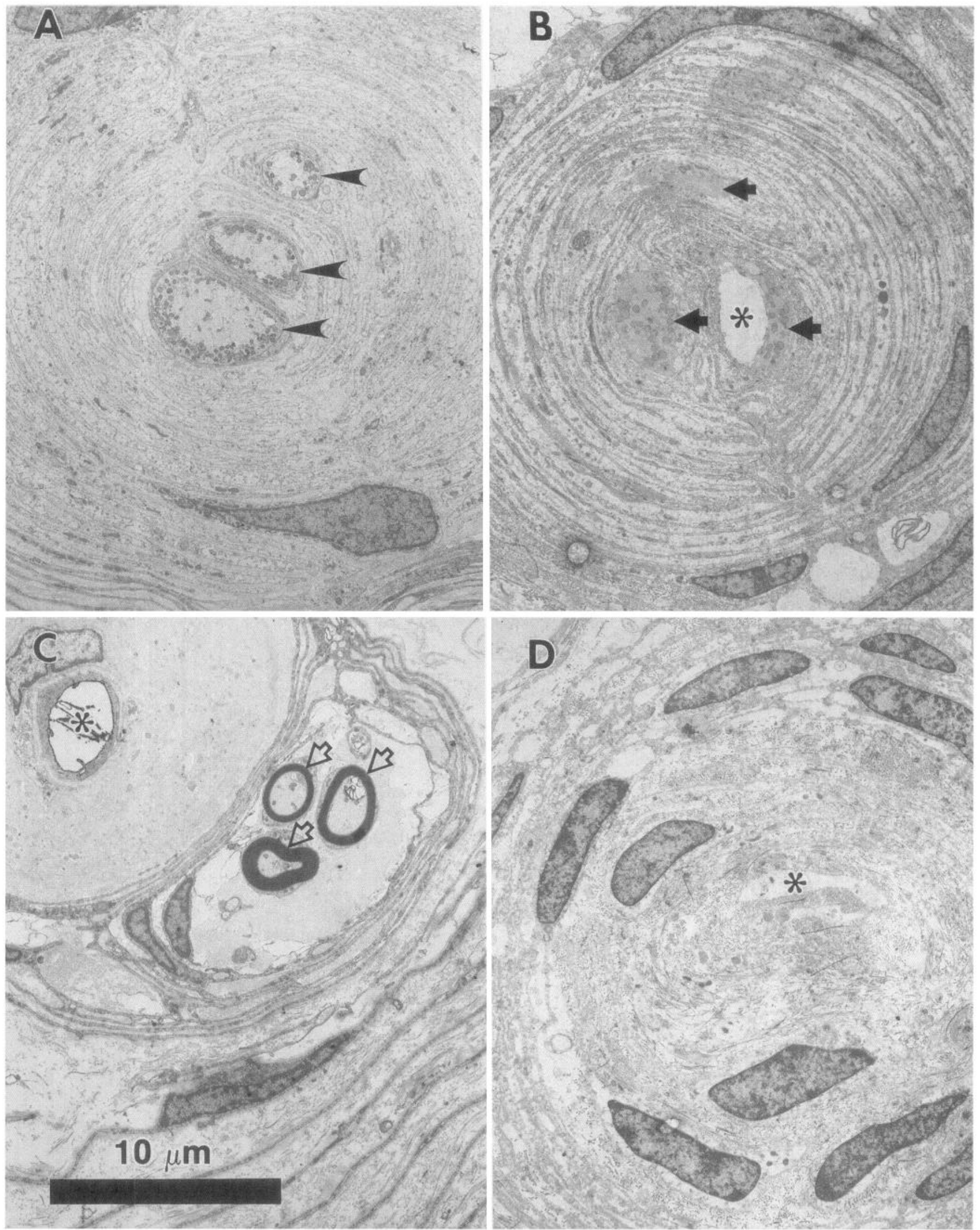

Figure 8. Electron micrographs of Pacinian corpuscles. Pacinian corpuscles were removed from the base of digits II and III following nerve repair, controls were removed from the base of digit V in the same hands. A, Transverse sections of normal Pacinian corpuscle, showing branched axon terminals occupying the inner core which are free of basal lamina and filled with mitochondria (arrows). B, Successful reinnervation of the inner 
lesion which causes distal Wallerian degeneration (Aitken and Thomas, 1962; Dyck et al., 1981; Hoffman et al., 1984). Direct evidence for this assertion was found in the present study where retrograde atrophy appeared pronounced even three and a half years after the nerve lesion as suggested by the thinner diameter of fibers and low g-ratio proximal to the nerve lesion compared to normal (see Morphological comparisons below).

Studies in man have shown functionally reinnervated sensory receptors to have thresholds at or below a movement of $50 \mu \mathrm{m}$ (Franzn and Lindblom, 1976; Hallin et al., 1979). An indentation of $100 \mu \mathrm{m}$ was used in order to be above the threshold of reinnervated receptors. In human sural nerve this procedure was considered to evoke responses from Pacinian corpuscles (Buchthal, 1982a). Indentations greater than $100 \mu \mathrm{m}$ or with deeper preindentation, elicited responses from joint and other sensory receptors in the hand. However, previous studies have demonstrated a 10 times higher density of Meissner corpuscles compared to Pacinian corpuscles in monkey fingers (DarianSmith and Kenins, 1980). Thus, contributions from Meissner corpuscles can not definitely be ruled out.

Responses evoked by tactile stimulation of the finger pad were present in all of the nerves tested (see Fig. 3). The amplitudes of the evoked responses were only half of those recorded in control median nerve, the latency was $50 \%$ longer than normal These characteristics are similar to those of fibers reinnervating touch receptors in man following peripheral nerve repair (Hallin et al., 1981a,b).

The "receptor" delay, or the time taken to convert a tactile stimulus to an electrically detectable action potential was three times longer than normal control. Using the same tactile stimulation apparatus, similar receptor delays were found in human median nerve graft repair (Krarup et al., 1990). Although many factors influence the abnormal reinnervation of skin, one structural explanation for the observed prolonged sensory receptor delays would be incomplete reinnervation patterns of Pacinian corpuscles, even at time periods of greater than three years. In support of this hypothesis, only approximately one in four $\mathrm{Pa}$ cinian corpuscles were found to be innervated (see Fig. 8).

Findings in the two $15 \mathrm{~mm}$ nerve repairs also suggest the utility of collagen nerve guides over longer nerve gap distances. These two nerves were previously repaired with a polylactate nerve guide and had reached stable recovery levels. Within 600$700 \mathrm{~d}$ following secondary repair with the collagen-based nerve guides, the nerves recovered to or exceeded the previously obtained CMAP amplitudes. It is impossible to know definitively from the present data whether the regenerated axons included some which had failed to grow through the first repair, but have now regenerated through the collagen nerve guide. Two lines of evidence suggest such a recruitment of previously failed axons. First, the CSAP amplitude increased in the median (30\%) and ulnar $(80 \%)$ nerves above the previously obtained levels. CSAP electrical potentials are an order-of-magnitude less than the CMAP because the recorded signal is produced by the stimulated nerve fibers themselves, rather than an amplification of the signals by muscle fibers. The CSAP is therefore considered a more direct estimate of the number of regenerated nerve fibers compared to the CMAP. Second, morphometric studies showed that the total number of myelinated fibers distal to the $15 \mathrm{~mm}$ collagen based nerve guide repair was similar to that found following the $5 \mathrm{~mm}$ entubulation repair, suggesting that there was not a reduction in the numbers of axons crossing the transection site.

\section{Delayed recovery and suture line tension}

The distance at which suture line tension becomes a problem is debatable, but most surgeons agree that a nerve gap distance within the hand or forearm of greater than a few centimeters (e.g., 2-5 cm) should not be directly coapted (Terzis et al., 1975; Millesi, 1981; Millesi and Meissl, 1981). Some surgeons believe that if a direct surgical repair can not be carried out with the limb in a neutral position suture line tension will become a factor at the repair site, resulting in axonal escape and the possibility of painful neuroma formation (Williams, 1987; Dellon and Mackinnon, 1988a).

In the present study suture line tension was minimized by mobilizing the proximal and distal nerve stumps for several centimeters prior to the repair procedure. Given the short segment of nerve removed $(5 \mathrm{~mm})$, and the mobilization of remaining nerve stumps, the direct suture procedure was considered to be a tensionless repair with the wrist in the neutral position. It is thus somewhat surprising that the direct suture group with a single suture line, which is considered to be the optimal clinical repair procedure, displayed slower rates of recovery than the nerve graft or nerve guide procedures. This result suggests that the comparatively small increase in suture line tension during wrist flexion produced by coaption of a $5 \mathrm{~mm}$ median nerve deficit, has a much greater affect on the rate of functional recovery than previously anticipated.

\section{Morphometric comparisons}

Nerve samples were taken for histological analysis from 752 to $1783 \mathrm{~d}$ following initial surgery (see Materials and Methods). Given this wide range, the question arises as to whether or not the morphological measurements hetween groups were influenced by the various survival times. The mean survival times were $1342 \pm 187 \mathrm{~d}$ and $1461 \pm 104 \mathrm{~d}$, respectively, for nerve graft and nerve guide groups. Statistical analysis of potential differences within each experimental group found no differences due to time of survival. A stable level of axonal maturation is also indicated by the physiological measurements which had plateaued by this time.

Both repair groups had approximately 1.5-2 times the number of myelinated axons distal to the nerve repair compared to proximal and normal control (Fig. 5A). Some previous studies have used axonal density alone as a measure of the efficacy of regeneration (e.g., Mackinnon and Dellon, 1990b). However, axonal density can be a poor indicator of the total number of regencrated axons due to differences in total cross sectional arcas

\section{$\leftarrow$}

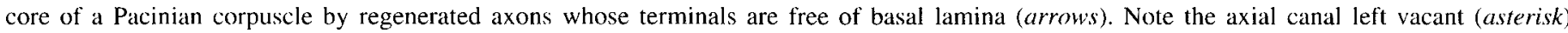

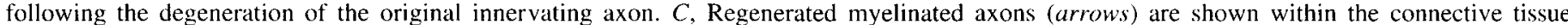

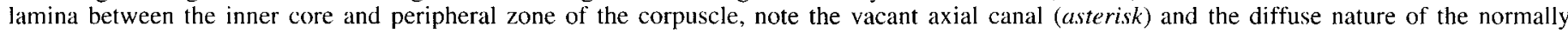

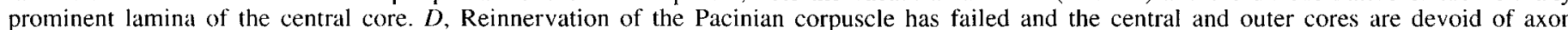

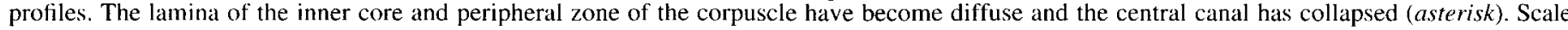
bar in $C$ applies to all panels. 
of the nerve trunks. In the present study the average endoneural cross-sectional area in the distal nerve trunks increased by $39 \%$ following nerve guide repair and decreased by $6 \%$ following graft repair. This resulted in a higher distal axonal density for the nerve graft group, but a lower total number of myelinated axons compared to the nerve guide group (Fig. $5 A, B$ ).

In normal peripheral nerve the individual contributions from each class of axons overlap and summate to produce a characteristic bimodal frequency distribution of fiber diameters (Sanders, 1947; Fernand and Young, 1951; Boyd and Davey, 1968; Friede and Beuche, 1985). In a population of regenerating and maturing myelinated axons the original bimodal fiber diameter distribution is replaced by a unimodal distribution with a narrower range (Simpson and Young, 1951). Previous studies have noted a return toward a bimodal distribution after extended recovery periods following freeze and crush injuries (Gutman and Sanders, 1943; Mira, 1979), the return of a bimodal distribution has not previously been conclusively demonstrated following nerve section and repair.

A partial recovery of the bimodal fiber diameter distribution was demonstrated in the present study (Fig. 6B,C). Although subtle, this observation was considered reliable due to the large sample size (800-1000 observations) from which the frequency distributions were generated. Examination of the distributions of the g-ratio versus fiber diameter scatterplots (Fig. 6E,F) did not readily demonstrate such a bimodal distribution. However, this relationship could only be demonstrated by a more complex representation of fiber diameter and g-ratio as three-dimensional surface plots. The construction of three-dimensional surface plots dramatically confirmed the suspected bimodal nature of the distal fiber diameter frequency distribution as a real characteristic of the data rather than random fluctuations (Fig. $7 B, C$ ).

The fiber diameter and g-ratio data demonstrate that, following extended periods of regeneration and maturation, subgroups of axons can eventually express their different growth rates and different levels of remyelination by their ensheathing Schwann cells. The recovery of a bimodal distribution of g-ratio versus fiber diameter relationship was seen in both of the repair groups, and again suggests the similarity of the two repair procedures. The maximum fiber diameter of the distal regenerated axons remained significantly below normal (Fig. 6C), and the increased g-ratios indicate thinner than normal myelin even at these extended time periods. The relative levels of myelination according to fiber diameter were also reversed following regeneration. In the normal axon population larger fibers had relatively thicker myelin sheaths (Fig. 6D), whereas in the regenerated population the smaller fibers had relatively thicker sheaths (Fig, 6E,F). These histological characteristics reflect processes that affect electrical conduction and are consistent with the physiological findings of reduced sensory nerve conduction velocities and increased latencies for the compound muscle action potentials that were found in our physiological assessments (see above).

There is a rich history regarding the search for effective clinical materials to repair severed peripheral nerves (Weiss, 1944; Woodhall and Beebe, 1956; Lundborg, 1988). Previous studies in the nonhuman primate have examined the ability of several materials to bridge damaged peripheral nerve. Recent studies have utilized polyglycolic acid (PGA) tubes (Dellon and Mackinnon, 1988b; Hentz et al., 1991), glycolide trimethylene carbonate (Maxon) tubes (Mackinnon and Dellon, 1990b), collagen tubes (Mackinnon and Dellon, 1990b), and sural nerve grafts (Hentz et al., 1991; Bain et al., 1992; Fish et al., 1992) to bridge several different nerve sites and gap distances. The survival time for these previous studies varied from as short as one week to 14 months, and all physiological assessments were carried out as terminal procedures. In all of these studies, none of the nerve guides tested performed consistently as well as a standard nerve autograft when judged by histological (fiber density and mean fiber diameter) or elctrophysiological criteria (nerve conduction velocity and amplitude). Isolated clinical reports have described the use of nerve guides fashioned from polyglycolic acid (Mackinnon and Dellon, 1990a) or silicone tubes (Merle et al., 1989; Lundborg et al., 1991) to repair human peripheral nerve. However complications have been reported with such materials such as extrusion from the repair site, kinking of a semirigid tube, neuroma formation, and persistent pain due to entrapment neuropathy associated with rigid nerve guide protheses (Merle et al., 1989; Mackinnon and Dellon, 1990a).

Some potential advantages of nerve guides compared to nerve graft repair include (1) the ability to have "off-the-shelf" prostheses that can be size-matched at the nerve repair site, (2) the avoidance of a second surgical procedure to harvest a donor nerve, (3) lack of axonal escape at suture lines, and (4) they could be used in locations that are normally very difficult to reach (e.g., some cranial nerves at the skull base). The ease and speed of nerve guide surgical implantation compared to the standard grafting procedure might facilitate the repair of nerves in cases of multiple trauma where vascular, orthopaedic, and neurological injuries necessarily take precedence and peripheral nerve repair is usually deferred to a later time.

An essential aspect of the collagen nerve guides described in this study compared to some of the materials listed above is that their bioresorption is complete and produces minimal scar tissue or inflammatory response (Archibald et al., 1991; Li et al., 1992). Therefore, there is less likelihood of entrapment of the anastomotic site due to scaring. The level of functional recovery has been stable over long time periods (3-4 years) without the episodes of compression neuropathy reported with other more rigid or non biodegradable materials (see above and Mackinnon et al., 1985; Urban and Bora, 1991).

The similar recovery of the nerves repaired with collagen nerve guides compared to the more standard procedures of nerve grafting or direct suture repair suggest that such prostheses may be useful in repair of human peripheral nerves, at least over short (5 mm) nerve gap distances. Further studies are warranted to test the efficacy of collagen-based nerve guides for the repair of longer nerve gap distances, the secondary repair of failed anastomoses, and the elimination of suture line tension.

\section{References}

Aitken JT, Thomas PK (1962) Retrograde changes in fibre size following nerve section. J Anat 96:121-129.

Archibald SJ, Krarup C, Li ST, Madison RD (1991) A collagen-based nerve guide conduit for peripheral nerve repair: an electrophysiological study of nerve regeneration in rodents and nonhuman primates. J Comp Neurol 307:1-12.

Bain JR, Mackinnon SE, Hudson $\Lambda R$, Wade J, Evans P, Makino A, Hunter RT (1992) The peripheral nerve allograft in the primate immunosuppressed with Cyclosporin A. I. Histologic and electrophysiologic assessment. Plast Reconstr Surg 90:1036-1046.

Ballantyne JP, Campbell MJ (1973) Electrophysiological study after surgical repair of sectioned human peripheral nerves. J Neurol Neurosurg Psychiatry 36:797-805.

Behse F (1990) Morphometric studies on the human sural nerve. Acta Neurol Scand [Suppl] 132:2-38.

Berry CM, Grundfest H, Hinsey JC (1944) The electrical activity of regenerating nerves in the cat. $\mathbf{J}$ Neurophysiol 7:103-115. 
Boyd JA, Davey MR (1968) Composition of peripheral nerves. London: Livingston.

Buchthal F (1982a) Human nerve potentials evoked by tactile stimuli. I. Maximum conduction and properties of compound potentials. Acta Physiol Scand [Suppl] 502:5-18.

Buchthal F (1982b) Human nerve potentials evoked by tactile stimuli. II. Stimulus parameters and recruitment of components. Acta Physiol Scand [Suppl] 502:19-32.

Buchthal F, Kuhl V (1979) Nerve conduction, tactile sensibility, and the electromyogram after suture or compression of peripheral nerve: a longitudinal study in man. J Neurol Neurosurg Psychiatry 42:436451 .

Buchthal F, Rosenfalck A (1966) Evoked action potentials and conduction velocity in human sensory nerves. Brain Res $3: 1-122$.

Cooney WP (1991) Median nerve repairs: the results of treatment. In: Operative nerve repair and reconstruction (Gelberman RH, ed), pp 379-391. Philadelphia: Lippincott.

Darian-Smith I, Kenins P (1980) Innervation density of mechanoreceptive fibers supplying glabrous skin of the monkey's index finger. J Physiol (Lond) 309:147-155.

Dellon AL, Mackinnon SE (1988a) Basic scientific and clinical applications of peripheral nerve regeneration. Surg Ann 20:59-100.

Dellon AL, Mackinnon SE (1988b) An alternative to the classical nerve graft for the management of the short nerve gap. Plast Reconstr Surg 82:849-856.

Dyck PJ, Lais AC, Karnes JL, Sparks M, Hunder H, Low PA, Windebank J (1981) Permanent axotomy, a model of axonal atrophy and secondary segmental demyelination and remyelination. Ann Neurol 9:575-583.

Dyck PJ, Gianni C, Lais A (1992) Pathologic alterations of nerves. In: Peripheral neuropathy, Vol 3 (Dyck P, Thomas PK, Griffin JW, Low PA, Poduslo JF, eds), pp 514-595. Philadelphia: Saunders.

Erlanger J, Schoepfle GM (1946) A study of nerve degeneration and regeneration. Am J Physiol 147:550-581.

Fernand YSV, Young JZ (1951) The sizes of the nerve fibres of muscle nerves. Proc R Soc Lond [Biol] 139:38-58.

Fields RD. Le Beau JM. Longo FM. Ellisman MH (1989) Nerve regeneration through artificial tubular implants. Prog Neurobiol 33:87134.

Fish JS, Bain JR, McKee N, Mackinnon SE (1992) The peripheral nerve allograft in the primate immunosuppressed with Cyclosporin A. II. Functional evaluation of reinnervated muscle. Plast Reconstr Surg 90:1047-1052.

Franzn O, Lindblom U (1976) Tactile intensity functions in patients with sutured peripheral nerve. In: Sensory functions of the skin in primates, with special reference to man (Zotterman Y, ed), pp 113118. Oxford: Pergamon.

Friede RL, Beuche W (1985) Combined scatter diagrams of sheath thickness and fibre calibre in human sural nerves: changes with age and neuropathy. J Neurol Neurosurg Psychiatry 48:749-756

Gutman E, Sanders FK (1943) Recovery of fiber numbers and diameters in the regeneration of peripheral nerves. J Physiol (Lond) 101: $489-518$

Hallin RG, Lindblom U, Wiesenfeld Z (1979) Psychophysical and neurophysiological methods to study patients with sensory disturbances. In: Sensory functions of the skin of humans (Kenshalo DR, ed), pp 23-35. New York: Plenum.

Hallin RG, Wiesenfeld Z, Lindblom U (1981a) Neurophysiological studies on patients with sutured median nerves: faulty sensory localization in nerve regeneration and its physiological correlates. Exp Neurol 73:90-106.

Hallin RG, Wiesenfeld Z. Lungnegard H (1981b) Neurophysiological studies of peripheral nerve functions after neural regeneration following nerve suture in man. Int Rehab Med 3:187-192.

Hentz VR, Rosen JM, Xiao SJ, McGill KC, Abraham G (1991) $\Lambda$ comparison of suture and tubulization nerve repair techniques in a primate. J Hand Surg US 16:251-261.

Hodes R, Larrabee MG, German W (1948) The human electromyogram in response to nerve stimulation and the conduction velocity of motor axons. Arch Neurol Psychiatry 60:340-365

Hoffman PN, Griffin JW, Price BL (1984) Control of axonal caliber by neurofilament transport. J Cell Biol 99:705-714.

Karnes J, Robb R, O'Brien PC, Lambert EH, Dyck PJ (1977) Computerized image recognition for morphometry of nerve attributes of shapc of sampled transverse sections of myelinated fibers which best estimates their average diameter. J Neurol Sci 34:43-51.

Krarup C, Gilliatt RW (1985) Some effects of prolonged constriction on nerve regeneration in the rabbit. J Neurol Sci 68:1-14.

Krarup C, Loeb GE, Pezeshkpour GH (1988) Conduction studies in peripheral cat nerve using implanted electrodes. II. The effects of prolonged constriction on regeneration of crushed nerve fibers. Muscle Nerve 11:933-944.

Krarup C, Upton J, Creager MA (1990) Nerve regeneration and reinnervation after limb amputation and replantation: clinical and physiological findings. Muscle Nerve 13:291-304.

Li ST, Archibald SJ, Krarup C, Madison R (1992) Peripheral nerve repair with collagen conduits. Clin Materials 9:195-200.

Lundborg G (1988) The nerve chamber as an experimental tool. In: Nerve injury and repair (Lundborg G, cd), pp 163-195. New York: Churchill Livingstone

Lundborg G, Dahlin LB, Danielsen N (1991) Ulnar nerve repair by the silicone chamber technique. Scand J Plast Reconstr Hand Surg 25:79-82.

Mackinnon SE, Dellon AL (1988) Median nerve entrapment in the proximal forearm and brachium: results of surgery. In: Surgery of the peripheral nerve (Mackinnon SE, Dellon AL, eds), pp 192-194. New York: Thieme.

Mackinnon SE, Dellon AL (1990a) Clinical nerve reconstruction with bioabsorbable polyglycolic acid tube. Plast Reconstr Surg 85:419424.

Mackinnon SE, Dellon AL (1990b) A study of nerve regeneration across synthetic (Maxon) and biologic (collagen) nerve conduits for nerve gaps up to $5 \mathrm{~cm}$ in the primatc. J Reconstr Microsurg 6:117121.

Mackinnon SE, Dellon AL, Hudson AR, Hunter RT (1985) A primate model for chronic nerve compression. J Reconstr Microsurg 1:185194.

Madison RD, Archibald SJ, Krarup C (1992) Peripheral nerve repair. In: Wound healing: biochemical and clinical aspects (Cohen IK, Diegelman F, Lindblad WJ, eds), pp 450-480. Philadelphia: Saunders.

Merle M, Dellon AL, Campbell JN, Chang PS (1989) Complications from silicone-polymer intubulation of nerves. Microsurgery 10:130 133.

Millesi H (1981) Reappraisal of nerve repair. Surg Clin North Am 61: $321-340$.

Millesi H, Meissl G (1981) Consequences of tension at the suture site. In: Posttraumatic peripheral nerve regeneration (Gorio A, Millesi H, Mingrino S, eds), pp 277-279. New York: Raven.

Mira JC (1979) Quantitative studies of the regeneration of rat myelinated nerve fibers: variations in the number and size of regenerating fibers after repeated localized freezings. J Anat 129:77-93.

Sanders FK (1947) The thickness of the myelin sheaths of normal and regenerating peripheral nerve fibres. Proc $\mathbf{R}$ Soc Lond [Biol] 135: 323-357.

Simpson SA, Young JZ (1951) Regeneration of fibre diameter after cross-unions of visceral and somatic nerves. Proc R Soc Lond [Biol] $139: 38-57$

Sunderland S (1991) The course of recovery after nerve repair. In: Nerve injuries and their repair: a critical appraisal (Sunderland S, ed), pp 499-504. New York: Churchill Livingstone.

Tallis R, Staniforth P, Fisher TR (1978) Neurophysiological studies of autogenous sural nerve grafts. J Neurol Neurosurg Psychiatry 41: $677-683$

Terzis JK, Faibisoff BA, Williams B (1975) The nerve gap: suture under tension versus graft. Plast Reconstr Surg 56:166-170.

Urban MA, Bora J (1991) Nerve grafting through resorbable tubes. In: Operative nerve repair and reconstruction (Gelberman RH, ed), pp 587-597. Philadelphia: Lippincott.

Weiss P (1944) The technology of nerve regeneration: a review, sutureless tubulation and related methods of nerve repair. J Neurosurg $1: 400-450$.

Williams HB (1987) The painful stump neuroma and its treatment. In: Microreconstruction of nerve injuries (Terzis JK, ed), pp 161-171. Philadelphia: Saunders.

Woodhall B, Beebe B (1956) Peripheral nerve regeneration. Washington, DC: US Government Printing Office.

Zar JH (1984) Comparing simple linear regression equations. In: Biostatistical analysis, Vol 2, pp 292-305. Englewood Cliffs, N.I: Prentice-Hall. 